SFB

Why do U.S. banks contribute

823

more to global systemic risk

Denefa Bostandzic, Gregor N.F. Weiß

Nr. 36/2013

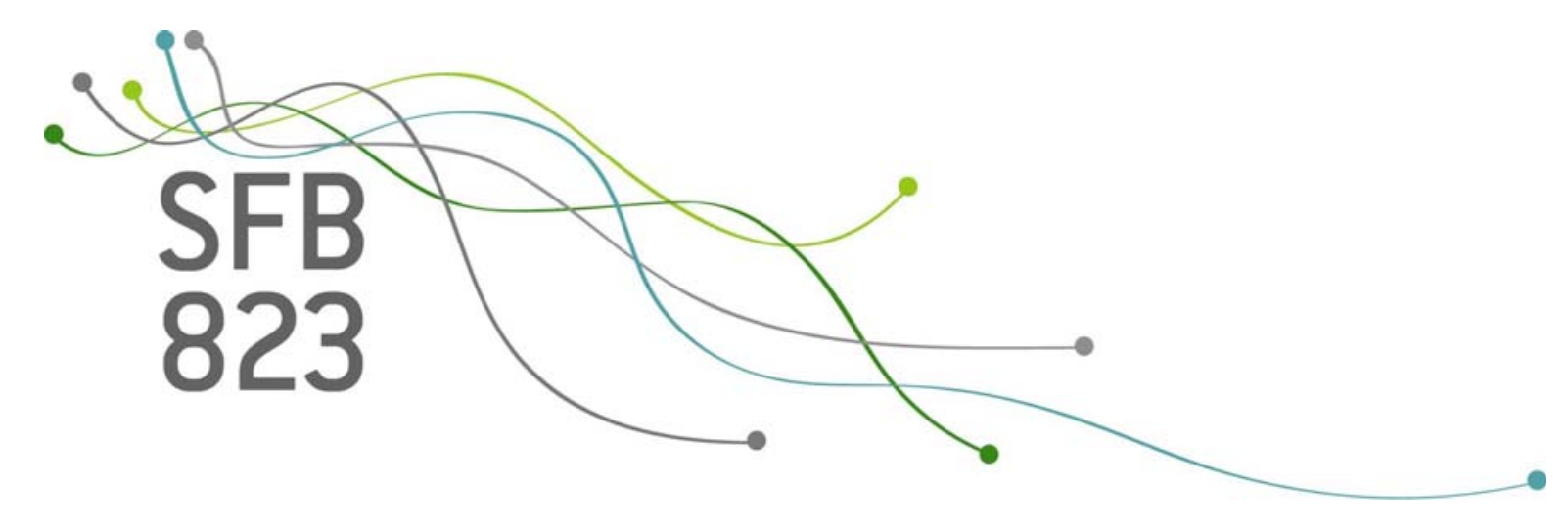





\title{
Why do U.S. banks contribute more to global systemic risk?
}

\author{
Denefa Bostandzic * \\ Fakultät für Wirtschaftswissenschaft, Ruhr-Universität Bochum \\ Gregor N.F. Wei $\beta^{\dagger}$ \\ Wirtschafts- und Sozialwissenschaftliche Fakultät, Technische Universität Dortmund \\ 29th September 2013
}

\begin{abstract}
We show that U.S. banks are more exposed and contribute more to systemic risk in the global financial system than European banks. We find that banks become systemically relevant if they rely too strongly on non-interest income, less traditional lending and if the quality of their loan portfolio decreases. More stringent capital regulations and more independent supervisory agencies improve financial stability. As we match European and U.S. banks based on firm size and valuation, the differences we find in the banks' systemic relevance cannot be explained by the too-big-to-fail or charter value hypotheses.
\end{abstract}

Keywords: Financial crises, systemic risk, bank regulation, non-interest income, capital regulation.

JEL Classification: G01, G21.

\footnotetext{
*Universitätsstraße 150, D-44780 Bochum, Germany, telephone: +49 23432 29437, e-mail: denefa.bostandzic@rub.de.

${ }^{\dagger}$ Corresponding author: Otto-Hahn-Str. 6a, D-44227 Dortmund, Germany, telephone: +49 231755 4608, e-mail: gregor.weiss@tu-dortmund.de. We received very useful comments from Tobias Adrian, Stefan Arping, Arnoud Boot, Claudia Buch, Charles Goodhart, Frank Heinemann, Christian Hirsch, Gerhard Illing, Andrew Karolyi, Josef Korte, Felix Noth, Steven Ongena, Andreas Pfingsten, Peter Raupach, Jean-Charles Rochet, Isabel Schnabel, Kenneth Singleton, Xavier Vives and participants of the DFG-MPI international conference on the structure of banking systems and financial stability and the DGF Annual Meeting 2013. Felix Irresberger, Janet Gabrysch, Sandra Gabrysch and Janina Mühlnickel provided outstanding research assistance. Support by the Collaborative Research Centers "Statistical Modeling of Nonlinear Dynamic Processes" (SFB 823) and "Economic Risk" (SFB 649) of the German Research Foundation (DFG) is gratefully acknowledged.
} 


\title{
Why do U.S. banks contribute more to global systemic risk?
}

\begin{abstract}
We show that U.S. banks are more exposed and contribute more to systemic risk in the global financial system than European banks. We find that banks become systemically relevant if they rely too strongly on non-interest income, less traditional lending and if the quality of their loan portfolio decreases. More stringent capital regulations and more independent supervisory agencies improve financial stability. As we match European and U.S. banks based on firm size and valuation, the differences we find in the banks' systemic relevance cannot be explained by the too-big-to-fail or charter value hypotheses.
\end{abstract}

Keywords: Financial crises, systemic risk, bank regulation, non-interest income, capital regulation. 
"The United States authorities were mistaken in permitting that bank to go to the wall. It has had very serious consequences for the world financial system [...]." Brian Lenihan, Jnr, Irish Minister for Finance, on the collapse of Lehman Bros. two weeks earlier

\section{Introduction}

Are U.S. banks unique in the sense that they contribute more to the systemic risk of the global financial sector than banks from other countries? 1 More specifically, why do U.S. banks contribute more to global systemic risk than comparable European banks of equal size and valuation? Since the recent financial crisis, there has been considerable discussion about the importance of the U.S. banking sector for the global financial system and why the financial distress at some U.S. institutions like Lehman Bros. was transmitted to other banks around the world. The collapse of Lehman Bros., however, is only one example of the anecdotal evidence pointing at a systematically higher contribution of U.S. banks to global financial fragility. The view that U.S. banks possess a higher systemic relevance for the global financial sector is also evidenced by the fact that eight out of the 28 banks that were considered as global systemically important (G-SIBs) by the Financial Stability Board (FSB) in November 2012 were headquartered in the U.S - the largest number for any country in the world. Yet, we know relatively little about the fundamental reasons for this hypothesized increased systemic importance of U.S. banks compared to European banks. Global systemic relevance, however, seems to be a phenomenon that is specific to European and U.S. banks, as only four banks outside the U.S. and Europe were classified as G-SIBs. In this paper, we document that U.S. banks contribute significantly more to systemic risk in the global financial system than European banks, especially during financial crises. After carefully testing the robustness of our finding, we address the question what causes these systematic differences between European and U.S. banks.

1 The Group of Ten (2001) defines systemic financial risk as the risk that an exogenous shock will trigger a loss of economic value in a substantial portion of a financial system causing significant adverse effects on the real economy. Recent studies by Adrian and Brunnermeier (2011) and Acharya et al. (2010) build on this definition and define a bank's contribution to systemic risk as the degree to which the bank contributes to an under-capitalization of the financial system. Throughout this paper, we adopt this definition of systemic risk. 
U.S. banks could be more globally systemically important than their European peers because of different business models and different sources of income. For example, U.S. banks could destabilize the global financial system more because of their more pronounced engagement in investment banking since the enactment of the Gramm-Leach-Bliley Act.2 Even if a U.S. bank does not offer investment banking services, it could still contribute more to global financial instability because of a more risk-seeking business model or a more aggressive risk culture. The comparison of the stock performance of European and U.S. banks shown in Figure 1 hints at the possibility that U.S. banks were indeed more risk-seeking than European banks during the two decades preceding the Subprime crisis. Conversely, U.S. banks appear to have suffered significantly more than European banks from the adverse effects of the crisis 3

Alternatively, differences in the global importance of European and U.S. banks could simply be due to differences in their regulation and supervision, the relative global importance of U.S. financial markets or other country-specific factors. Most prominently, the systemic risk stemming from U.S. banks during the financial crisis has been attributed by some commentators to the lax regulation of U.S. banks before the crisis (see Stiglitz, 2010). Testing these hypotheses contributes significantly to our current understanding of the drivers of global systemic risk. The results we find, however, are also of major importance to policymakers for deriving strategies that aim at strengthening global financial stability.

We use three different models for measuring an individual bank's exposure and contribution to systemic risk that are all well founded by economic theory. First, we follow Acharya et al. (2010) and employ a bank's Marginal Expected Shortfall (MES) to measure its exposure to a possible under-capitalization of the financial sector. 4 They define a bank's MES as the bank's mean stock return during the 5\% worst days for the global financial sector. While Acharya et al. (2010) estimate the MES in a static fashion, Brownlees and Engle (2012) propose a dynamic specification

2 This view is shared, e.g., by Paul Krugman who argued that "[...] aside from Alan Greenspan, nobody did as much as Mr. Gramm to make this crisis possible" (New York Times, Taming the beast, March 24, 2008).

3 For a detailed analysis of the effects of the financial crisis on systemic risk in the European banking sector, see Acharya and Steffen (2012).

$4 \quad$ Brunnermeier et al. (2012) refer to the MES as the realized Systemic Expected Shortfall. 
of the estimation of a bank's MES. In our main analyses, we focus on annual averages of the daily MES estimates (which we call dynamic MES for simplicity) as the dynamic specification accounts for time varying volatility and correlation as well as nonlinear tail dependence in the banks' and the financial sector's returns 5 Next, we use the closely related $\Delta$ CoVaR measure of Adrian and Brunnermeier (2011) to estimate an individual bank's contribution to the fragility of the financial sector. Finally, as a third measure of systemic relevance that combines a measure of a bank's stock price sensitivity together with its leverage, we make use of the SRISK measure proposed by Acharya et al. (2012) and Brownlees and Engle (2012) 6

Using these three measures of systemic risk, we then test several hypotheses from the financial intermediation and international finance literature on the question why U.S. banks might have a higher exposure and contribution to the fragility of the global financial sector. In the former, a bank's size and valuation are often cited as the main drivers of systemic risk. While larger banks could become too-big-to-fail and provide managers with incentives for excessive risk-taking (see O'Hara and Shaw, 1990; Acharya and Yorulmazer, 2008), the opposite result could be caused by an increased charter value (see Matutes and Vives, 2000). Gandhi and Lustig (forthcoming) document a size effect in bank stock returns as a bank's tail risk and its probability of receiving a bailout are priced by stock market investors. As a result, the systemic risk contribution of European and U.S. banks could differ simply due to mere differences in the banks' size. 7 In this paper, however, we build on several recent papers on the financial crisis that argue that a bank's size and market-tobook ratio cannot fully explain its contribution to systemic risk. Hovakimian et al. (2012) analyze quarterly data of U.S. banks over the period of 1974 to 2010 and find that systemic risk is driven by size, leverage and asset risk. In addition to these factors, Brunnermeier et al. (2012) hypothe-

$5 \quad$ To keep our results comparable to earlier works by Acharya et al. (2010) and Brunnermeier et al. (2012), however, we also estimate but do not report results on the static MES. We find the results for the static MES to be similar to those for the dynamic MES.

6 The need for the use of several alternative systemic risk measures is stressed by the findings of Giglio et al. (2013) who show that most systemic risk measures reveal low predictive power for macroeconomic downturns (but not necessarily financial crises) if taken individually. Their predictive power, however, increases significantly if used in a parsimoniously aggregated index.

7 In the theoretical model of Acharya et al. (2010), a bank's MES is scaled by its common equity and should thus not be driven merely by size. Nevertheless, Brunnermeier et al. (2012) find a strong positive correlation between MES and bank size in their empirical study. 
size and confirm that non-core activities of banks in the form of non-interest income significantly increased the contribution of U.S. banks to systemic risk between 1986 and 2008. 8 The insight that systemic risk is not solely driven by bank size is also shared by regulators. For example, the Basel Committee on Banking Supervision (2013) identifies a bank's interconnectedness, substitutability, global (cross-jurisdictional) activity and its complexity as further key drivers of financial instability. Consequently, U.S. banks could ceteris paribus be more systemically relevant than European banks because of a stronger activity in non-core businesses or because of more interconnections with the rest of the financial sector. Other commentators have highlighted the reliance of some banks on short-term funding as a major reason for the build-up of systemic risks prior to the crisis (see, e.g., Diamond and Rajan, 2009; Adrian and Shin, 2010; Gorton, 2010). Again, differences in the systemic risk contribution of European and U.S. banks could simply be due to systematic differences in the funding fragility of these banks. A different explanation for the differential performance of banks during the financial crisis is given by Fahlenbrach et al. (2012) who show that a bank's stock return performance during the LTCM crisis predicts the bank's performance and its default probability during the Subprime crisis. They attribute this finding to persistence in a bank's risk culture. Following this line of argumentation, U.S. banks could contribute more to global systemic risk due to a more aggressive business model or the often cited casino mentality of U.S. firms (see, e.g., Bartram et al., 2012).

We also explore hypotheses that the differences in the systemic risk exposure and contribution of European and U.S. banks we find are not due to idiosyncratic but country-specific factors. There is increasing evidence in the empirical banking literature that the design of national regulatory systems and deposit insurance schemes can both stabilize and destabilize the financial system. For instance, Demirgüç-Kunt and Detragiache (2002) confirm hypotheses stated by Merton (1977) and Keeley (1990) that the presence of an explicit deposit insurance is associated with less financial stability. In contrast, the relation between regulation and financial stability is much less clear.

$8 \quad$ The hypothesis of banks' non-core activities causing an increase in systemic risk is also in line with the theoretical models of Song and Thakor (2007) and Shleifer and Vishny (2010) and the empirical findings of DeYoung and Torna (in press). 
While several studies find that stronger regulation (see Barth et al., 2004) and supervision (see Buch and DeLong, 2008) can reduce aggregate bank risk-taking, Beltratti and Stulz (2012) find no evidence that stronger regulation led to a better performance of banks during the Subprime crisis. 9 Thus, it seems natural to ask whether U.S. banks have a stronger influence on the global financial sector because of a regulatory regime that differs significantly from those in European countries.

Finally, our investigation into the determinants of a bank's systemic risk contribution is also guided by the rich literature on international finance. In this field of research, Bekaert and Harvey (1997) and Baele (2005) argue that the globalization process, trade integration and equity market development may have gradually increased the interdependence of global equity markets. Banks in the U.S. could thus be more relevant for the global financial sector because of the strong interdependencies between the U.S. financial sector and the rest of the world enabling adverse effects from U.S. banks to easily spill over to financial sectors in foreign countries. Contrasting these findings, a recent study by Bekaert et al. (2012) on the Subprime crisis does not find economically significant evidence in favor of what the authors label the "U.S. contagion hypothesis". They also reject the "globalization hypothesis" which states that crises should hit hardest highly globally integrated economies (e.g., through financial linkages). However, their work is concerned with equity market contagion and not financial stability leaving the hypothesis that financial integration influences the average exposure and contribution of domestic banks to global systemic risk untested. As such, U.S. banks could still contribute disproportionately more to global financial instability (especially during crises) than banks from countries which are less interconnected with global financial markets. Similarly, banks from the U.S. could be more globally relevant due to the more developed and open financial sector they operate in. Greater financial development and capital market openness have been shown to increase idiosyncratic firm risk. While greater financial development leads to a more efficient risk diversification among firm owners (see Michelacci and Schivardi, forthcoming), capital market openness reduces a firm's cost of capital (see Bekaert and Harvey, 2000) and agency costs (see Stulz, 1999), with both effects enabling managers to engage in riskier

9 In a related study, Laeven and Levine (2009) find that the relation between bank risk and capital regulations, deposit insurance policies, and restrictions on bank activities depends critically on each bank's ownership structure. 
projects. Furthermore, investor protection is known to be positively related to idiosyncratic firm risk (see, e.g., Stulz, 2005). As investor protection improves, corporate insiders have less opportunities to appropriate corporate resources as personal benefits thus inducing riskier but value enhancing investment policy (see John et al., 2008). Conversely, Acharya et al. (2011) show that creditor rights are associated with reduced corporate risk-taking. Thus, U.S. banks could also contribute less to global systemic risk than European banks because of better creditor rights in the U.S. than in some European countries.

Analyzing a sample of 4,892 bank-year observations over the period from 1991 to 2011, we find U.S. banks to have an average annual dynamic MES that is 132 basis points higher than the average dynamic MES of European banks of matching size and valuation. This result is both statistically and economically significant. As we match European banks to U.S. banks based on their total assets and firm value, the differences that we find in the banks' dynamic MES cannot be explained by simple differences in bank size. Moreover, this significantly higher exposure of U.S. banks to global systemic risk is persistent over our complete sample and particularly pronounced in the aftermath of both the LTCM and the Subprime crises. Concerning the contribution of U.S. banks to global systemic risk, we find a similar result with U.S. banks having an average annual $\Delta \mathrm{CoVaR}$ that is 16 basis points lower than that of European banks.

We find that banks are more exposed to fragility in the global financial sector if they rely more strongly on non-interest income, grant fewer loans, and had worse stock performance in the past. Our evidence thus supports the view that non-traditional banking imposes externalities on the global financial sector in the form of an increased exposure of individual banks to systemic crises. For large banks, a higher interconnectedness with the global financial system significantly increases its exposure to systemic risk. We also find that a bank's marginal exposure and contribution to global systemic risk is negatively correlated with more stringent capital requirements and a more independent supervisory agency. Finally, supporting the view that better shareholder rights could induce riskier investment policies at a bank, we find the banks' exposure to systemic risk to be increasing in investor protection. 
Our paper is related to several recent papers on systemic risk and the financial crisis. Brunnermeier et al. (2012) analyze the systemic risk contribution of U.S. banks during the financial crisis concentrating on the correlation between banks' non-interest income and systemic risk. In our work, in contrast, we analyze European and U.S. banks that we match based on firm size and valuation. Beltratti and Stulz (2012) and Fahlenbrach et al. (2012) investigate the drivers of banks' buy-and-hold stock returns during the recent crisis. The relation between capital and performance in the form of a bank's survival and market share during bank crises, market crises, and normal times in the US is studied by Berger and Bouwman (2013). While their focus is on bank performance, however, we focus on banks' contribution to global systemic risk. Finally, we follow Bartram et al. (2012) and match European and U.S. firms using propensity score matching based on firm size and valuation. 10 But unlike their investigation into stock volatility, we employ a matching procedure to analyze the drivers of systemic risk beyond the too-big-to-fail and the charter value hypotheses.

The paper proceeds as follows. In Section 2, we describe our data and outline our procedure for matching European banks to U.S. banks of equal size and valuation. In Section 3, we document our main finding that U.S. banks are more relevant for the global financial sector than their European peers. In Section 4, we investigate why U.S. banks are more systemically relevant than European banks. Section 5 concludes.

\section{Data}

This section describes the construction of our sample, defines the different systemic risk measures and presents the choice of our main independent variables as well as descriptive statistics of our data.

$\overline{10}$ Propensity score matching of banks based on firm size is also done, e.g., by Schaeck et al. (2012) who analyze the effects of executive turnovers at banks. 


\subsection{Sample construction}

Our primary sample consists of all publicly traded European and U.S. banks included in the country lists and dead firm lists in Thomson Reuters Financial Datastream.11 We consider a bank's country to be the country of its primary listing and therefore exclude all secondary listings and nonprimary issues. Also, we do not include U.S. OTC Bulletin Board and "Pink Sheet" stocks, investment trusts and exclude stocks with missing nation code (data item WC06027) in Thomson Worldscope. Our sample thus includes 1,476 U.S. and 338 European banks from 33 countries. Bank-level data from 1991 through 2011 are constructed from two sources. Daily share price data are retrieved from Thomson Reuters Financial Datastream while financial accounting data are taken from the Worldscope database 12 All stock market and accounting data are collected in U.S. dollars to minimize a possible bias in our results stemming from currency risk.

Additionally, we winsorize accounting data at the $1 \%$ and $99 \%$ quantile to minimize the biasing effect of outliers. For each year, we require share price data to be available for the full year from Datastream so that we have sufficient data points for the dynamic estimation of a bank's daily MES. Furthermore, we require lagged annual accounting data not be missing from Worldscope for a bank to enter our sample (otherwise the respective bank-year observation is dropped from the sample). Next, we perform several screening procedures as proposed by Ince and Porter (2006) on the daily returns on banks' stock prices to account for known data errors in Datastream. First, we require a minimum share price of $\$ 1$ for a bank to be included in our sample. Additionally, any return above 300 percent that is reversed within one month is treated as missing. Following Hou et al. (2011), we also exclude bank-years, if the number of zero return days is more than 80 percent in a given month of that year. To exclude non-trading days, we define days, on which 90 percent or more of the stocks listed on a given exchange have a return equal to zero, as non-trading days.

11 We thus allow banks to default over our sample period to minimize an otherwise possible survivorship bias.

12 Banks in Datastream and Worldscope are matched based on their Datastream code as a common identifier. Several banks are included in Datastream with listings in different countries and with more than one share class. We therefore screen on the security type and control for multiple listings and share classes. 
The exclusion of bank-years from our analysis due to missing or incomplete data might induce a selection bias into our sample as the missing data might be due to the respective bank being opaque. To address concerns about possible bank opacity, we control for this bias in a two-step manner. First, we rule out a selection bias for those banks omitted from our analysis for which the data extracted from Datastream or Worldscope is only incomplete and for which key data items (like, e.g., total assets) are available. Second, we manually check for the remaining banks whether we can find at least one annual report and stock quotes from the respective bank from a publicly accessible data source if Datastream does not provide any data. The results of this check rule out the possibility of a selection bias stemming from bank opacity.

We also control for mergers between matched banks in our sample. Several studies (see, e.g., De Nicolò and Kwast, 2002) argue that consolidation in banking coincides with an increase in systemic risk. Wagner (2010) finds the related, counterintuitive, result that more diversified banks increase systemic risk. As takeover activities increased in the banking sector during the last decades, our results could be biased by the presence of merging banks in our sample. To rule out such a biasing influence of bank mergers, we exclude both the acquirer and the target in the year in which a merger took place. The merging banks are identified by manually searching the Thomson One Banker Database. Our final sample thus excludes banks that merged during the observation year and comprises banks that can be subdivided into either primary commercial banks (SIC codes 6021, 6022 and 6029) or savings institutions (SIC codes 6035 and 6036).

In total, our sample contains 4,892 bank-year observations with the number of matched U.S. banks increasing steadily from 33 banks in 1991 to 207 banks in 2011. The distribution of bankyears across countries in our sample is shown in Figure 2. Not surprisingly, Switzerland, France and Italy have the largest numbers of bank-years among European countries in our sample. Conversely, emerging countries like, e.g., Slovenia, Latvia and Serbia enter the sample with less than ten bank-years with most of these few bank-years coming from the period after the financial crisis. 


\subsection{Systemic risk measures}

We proxy for the relevance of a bank for the global financial system by using three measures based on daily stock market and financial accounting data. Our choice of these systemic risk measures is motivated by the fact that these measures have been extensively discussed in the literature and are also used by regulators and central bankers for monitoring financial stability (see Benoit et al., 2013) 13 First, we follow Acharya et al. (2010) and employ the Marginal Expected Shortfall which is a static structural form approach to measure an individual banks' exposure to systemic risk and which is defined as the negative mean net equity return of the bank conditional on the global financial market experiencing extreme downward movements. 14 To proxy for the global financial sector, we use the World Datastream Bank Index (DS code BANKSWD). 15 Next, we compute daily MES estimates in all years using the dynamic model of Brownlees and Engle (2012). Their approach is econometrically more challenging than the static MES due to the fact that it accounts for time varying volatility and correlation as well as nonlinear tail dependence in the banks' and sector's returns. We employ the TARCH (see Rabemananjara and Zakoïan, 1993) and Dynamic Conditional Correlation (DCC) (see Engle, 2002) specifications for computing daily MES estimates for all trading days within one year. The daily MES estimates are then averaged for each bank-year to yield our first dependent variable 16

Additionally, we also implement the $\Delta \mathrm{CoVaR}$ method proposed by Adrian and Brunnermeier (2011), which is based on the tail covariation between financial institutions and the financial system. Adrian and Brunnermeier (2011) criticize the MES measure as not being able to adequately

13 Since the recent financial crisis, several other measures of systemic risk have been proposed in the literature. Further examples for such measures apart from those used in this study are due to De Jonghe (2010); Huang et al. (2011); Schwaab et al. (2011); Hautsch et al. (2012); Hovakimian et al. (2012) and White et al. (2012). The systemic risk measures we employ, however, share the property that they are all based on economic theories of bank regulation.

14 We follow Acharya et al. (2010) and use the 5\% quantile to define extreme downward shocks of the financial sector index.

15 The focus of our paper lies on the systemic relevance of banks (and not other financial institutions like, e.g., insurers) to financial instability. Consequently, we opted for the use of a global bank sector index for calculating our three measures of systemic risk in our main analysis. None the less, we also use an index of the global financial sector in our robustness checks.

16 Annual estimates of systemic risk contributions are also analyzed by Brunnermeier et al. (2012) while quarterly estimates are studied by Hovakimian et al. (2012). 
address the procyclicality that arises from contemporaneous risk measurement. 17 Most importantly, MES can be seen as a measure of a bank's exposure to turmoil in the financial market whereas $\Delta \mathrm{CoVaR}$ attempts to measure a bank's contribution to systemic risk. In our study, we additionally estimate the conditional as well as the unconditional $\Delta \mathrm{CoVaR}$ for each bank-year in our sample. While the unconditional $\Delta$ CoVaR estimates are constant over time, 18 the conditional $\Delta \mathrm{CoVaR}$ is time-varying and estimated using a set of state variables that capture the evolution of tail risk dependence over time.19

Next, both MES and $\triangle$ CoVaR could be criticized for being based on stock market data only and for not taking into account the leverage of a financial institution. As such, both MES and $\Delta$ CoVaR could simply be substitutes for a bank's beta as both measure the sensitivity of a bank's equity to changes in market returns. To rectify this shortcoming, Acharya et al. (2012) and Brownlees and Engle (2012) propose a Systemic Risk Index (SRISK) to measure the expected capital shortfall of a bank in a crisis. The SRISK estimate for bank $i$ at time $t$ is given by

$$
\operatorname{SRISK}_{i, t}=k\left(\operatorname{Debt}_{i, t}\right)-(1-k)\left(1-\operatorname{LRMES}_{i, t}\right) \text { Equity }_{i, t}
$$

where $k$ is set to $8 \%$ to denote the regulatory capital ratio, $D e b t_{i, t}$ is the bank's book value of debt, $L_{R M E S}{ }_{i, t}$ is the long run Marginal Expected Shortfall defined as $1-\exp (-18 \cdot$ dynMES $)$, dynMES is the previously described dynamically estimated MES and Equity ${ }_{i, t}$ is the banks's market value of equity. To address concerns that MES and $\triangle \mathrm{CoVaR}$ do not account for the effect of leverage on a bank's systemic relevance, we employ SRISK as a further measure of a bank's contribution to financial fragility. Technical details of the methods used for estimating the different measures of systemic risk are described in Appendix A

17 Conversely, Acharya et al. (2010) criticize the $\Delta$ CoVaR measure as being based on a non-coherent risk measure. 18 We do not report the results for the unconditional $\Delta \mathrm{CoVaR}$ estimations. They are available from the authors upon request.

19 We follow Adrian and Brunnermeier (2011) in using the change in the three-month Treasury bill rate, the difference between the ten-year Treasury Bond and the three-month Treasury bill rate, the change in the credit spread between BAA-rated bonds and the Treasury bill rate, the return on the Case-Shiller Home Price Index, and implied equity market volatility from VIX as state variables in the estimation of the conditional $\Delta \mathrm{CoVaR}$. 
Finally, we also compute banks' annual buy-and-hold returns for each year.20 The anecdotal evidence presented in Figure 1 hints at the fact that U.S. banks performed significantly better than European banks. During the course of our study, we intend to investigate in more detail the question whether U.S. banks contribute more to global systemic risk due to or despite their better stock market performance in the past.

\subsection{Main independent variables}

We investigate the hypothesis that the differences in the annual MES of European banks and their matching U.S. banks can be explained with idiosyncratic bank characteristics and countryspecific factors. To this end, we collect a set of variables that cover bank characteristics, the banks' macroeconomic and regulatory environment as well as the individual bank's risk culture. All variables used in our study as well as their respective data sources are defined in Table B.1 in the Appendix.

The first set of variables we use includes standard idiosyncratic bank characteristics. We use the natural logarithm of a bank's total assets to proxy for bank size and a bank's market-to-book ratio defined as the book value of common equity divided by the market value of common equity to proxy for the bank's valuation. We would expect bank size to be an economically significant driver of systemic risk, regardless of the home country of a bank. In line with the too-big-to-fail hypothesis, an increased probability of a government bailout in case of default could cause managers to engage in excessively risky projects (see Gandhi and Lustig, forthcoming). Conversely, banks with greater charter value could provide managers with incentives to have higher capital ratios and to limit their risk-taking to insure against losses in charter value in case the bank defaults (see also Keeley, 1990). A bank's valuation and its systemic risk contribution could thus be negatively correlated. Although the significant relation between both variables and systemic risk has been shown in various previous studies, our study takes a step into a different direction. Instead of using bank

20 Bank performance during the financial crisis is studied extensively by Beltratti and Stulz (2012) and Fahlenbrach et al. (2012). 
size and valuation as explanatory variables in our regressions, we match European banks to U.S. banks (with replacement) based on these two variables. Our hypothesis is that banks in the U.S. could contribute significantly more to global systemic risk for reasons that go beyond sheer size or valuation.

As a first explanatory variable, we employ the variable Leverage which is defined as the quasimarket value of assets divided by the market value of equity in which the quasi-market value of assets is given by the book value of assets minus the book value of equity plus the market value of equity (see Acharya et al., 2010). Brunnermeier et al. (2012) as well as Beltratti and Stulz (2012) confirm hypotheses that highly levered banks contribute more to systemic risk and performed worse than lower levered banks during the recent financial crisis. These findings are also underlined by Shleifer and Vishny (2010) who confirm that highly levered banks do not only contribute more to systemic risk, but also to higher economic volatility. Contrasting these arguments, Berger and Bonaccorsi di Patti (2006) find that managers at banks with low leverage are inclined to commit free cash flows to risky projects thus increasing the likelihood of the bank's default, and consequently, its contribution to systemic risk. As a result, we expect the sign of leverage to be unrestricted in our regressions.

The second explanatory variable we consider is Non-interest income, which is defined as the ratio of a bank's non-interest income to total income.21 Brunnermeier et al. (2012) empirically show that banks with higher non-interest income have a higher contribution to systemic risk. The authors trace this notion back to the fact that non-core banking activities like, e.g., investment banking, are different from the traditional deposit taking and lending functions of banks.22 This line of argumentation is also supported by the evidence of DeYoung and Torna (in press) who show that higher non-interest income from non-traditional activities that require banks to make asset investments significantly increases a bank's default probability. Consequently, we expect our variable Non-interest income to be highly significant and positively correlated with a bank's

$\overline{21}$ We also repeat our analyses using Total assets as the denominator in Non-interest income and find qualitatively and quantitatively similar results.

22 Similar arguments have been stated in explanations of the systemic importance of insurers, like, e.g., AIG (see Cummins and Weiss, 2010). 
systemic risk contribution. We also use the variable Loans defined as the ratio of a bank's total loans to total assets. We expect the variable Loans to have a differential influence on systemic risk. On the one hand, a higher loans-to-assets ratio could be indicative of a more traditional business model. Contrary to the arguments brought forward in connection with banks' non-interest income, the systemic importance of banks could be negatively correlated with the degree to which these banks relied on granting loans. On the other hand, banks that grant more loans could have a higher exposure to credit contagion (see Jorion and Zhang, 2007). Bartram et al. (2007) argue that payment failures might lead to an increase in a bank's loan defaults resulting in an increase in the bank's likelihood of becoming insolvent.23 Also, Beltratti and Stulz (2012) argue that banks with fewer loans could be holding more credit-risky securities which could make them more susceptible to increases in credit spreads. Further, we consider a bank's loan loss provisions defined as the natural logarithm of expenses set aside as an allowance for uncollectable or troubled loans in our regressions. The variable Loan loss provisions proxies for the quality of a bank's loan portfolio. Consequently, we expect a positive relation between loan loss provisions and a bank's contribution to systemic risk.

In our regressions, we also include the variable Debt Maturity which is defined as the ratio of total long term debt to total debt. Shleifer and Vishny (2010) argue that the cyclicality of credit risk-taking and the use of short-term debt contributed to the financial crisis. More precisely, the dependence of certain banks on short-term funding exposed these institutions to liquidity risks during the financial crisis and ultimately led to significant systemic risks (see Brunnermeier and Pedersen, 2009). Based on these findings, the authors of both studies argue that direct regulation of shortterm borrowing by banks is needed, amongst others, to dampen cyclical credit fluctuations and to control for systemic risk. Similarly, Fahlenbrach et al. (2012) find empirical evidence that banks that performed poorly during the recent crisis were more reliant on short-term funding than other banks. Consequently, we expect Debt maturity to be negatively correlated with systemic risk.

The next bank-specific variable we consider in our main regressions is Deposits, which is de-

$23 \quad$ This view is supported by the evidence found by Foos et al. (2010) who show that loan growth leads to a peak in loan loss provisions and lower capital ratios. 
fined as total deposits to total liabilities. Complementing the arguments of Brunnermeier et al. (2012), banks with a higher portion of deposit taking (and thus a less fragile funding) should contribute less to systemic risk than banks engaging more strongly in non-core banking activities. 24 Following Fahlenbrach et al. (2012), we also use the buy-and-hold returns of a bank lagged by one year (variable Performance) as a proxy for persistence in a bank's risk culture. Our prediction is that banks that performed well in the past stick to their (successful) culture of taking risks and contribute less to systemic risk. Finally, we also use the variable Liquidity beta to proxy for a bank's exposure to illiquid assets. If a bank invests in illiquid assets, its exposure to liquidity beta could impede the bank's ability to reduce its balance sheet and to avoid financial distress. Liquidity betas are estimated as the regression liquidity beta of a bank's excess return on the market-wide liquidity innovations of Pástor and Stambaugh (2003) which are computed from data for the three years preceding a respective bank-year. As conjectured by the Basel Committee on Banking Supervision (2013), the contribution of a bank to the fragility of the financial sector could also be driven by the bank's interconnectedness with the global financial system (see also Black et al.,, 2012). To proxy for a bank's interconnectedness, we use the meausure proposed by Billio et al. (2012) based on principal component analysis applied to the stock returns of all banks in our sample. We expect this proxy to be positively related to both a bank's exposure and contribution to systemic risk.

We also investigate whether regulatory, macroeconomic and other country-specific characteristics (besides idiosyncratic bank characteristics) can explain the differences in the systemic risk contribution of European and U.S. banks. Several of these country-specific variables are not available for our full sample period. However, all of these variables show little to no time variation so that we update missing data points with the most recent data that is available to us.25 First, we employ data on the power and independence of a country's banking supervisory authority from the database of Barth et al. (2006) (and updated in Barth et al., 2013). The stringency of capital

$24 \quad$ All countries in our sample have an explicit deposit insurance scheme. In these cases, in contrast to money market funding, deposit funding is thus not subject to runs (see Gorton, 2010) and higher values of Deposits should clearly have a stabilizing effect on the financial system. As we will discuss later, however, the presence of an deposit insurance scheme on the other hand could induce a moral hazard problem.

25 Barth et al. (2004) find the similar result that most of their variables do not show significant time variation. 
regulations in a given banking system is proxied by the country's Capital Regulatory Index. The index ranges from zero to ten with higher values denoting greater stringency. Next, the variable Independence of Supervisory Authority measures the degree to which the supervisory authority is independent of the executive branch of government. We also use the Official Supervisory Power Index which measures the extent to which supervisory authorities have the authority to discipline banks by taking specific actions to prevent and correct problems. For all three variables, we expect stricter supervision and regulation to have a limiting influence on systemic risk.

Empirical evidence suggests that the risk taking of banks is sensitive to domestic regulation and in particular, restrictions on bank activities and market entry (see Barth et al., 2004; Laeven and Levine, 2009; Buch and DeLong, 2008)26 As a result, differences in the exposure and contribution to systemic risk could be driven by differences in the way regulators prohibit banks from engaging in certain business activities or shield markets from foreign competitors. We use an index that captures these differences in banking regulation. To be precise, we use an index of the overall restrictions on bank activities that measures the extent to which a bank can both engage in securities, insurance, and real estate activities and own nonfinancial firms.Data on this variable Restrictions are taken from the database of Barth et al. (2013). Finally, we also employ their Private monitoring index that captures the incentives and capabilities provided by regulatory and supervisory authorities to encourage the private monitoring of banks.

Additionally, we use several variables to characterize the design of deposit insurance schemes that are implemented in our sample banks' home countries. Data on deposit insurance schemes are taken from the database of Demirgüç-Kunt et al. (2008). The first variable we use is Coverage limit which is defined as the coverage limit of the deposit insurance scheme in local currency divided by GDP per capita. We expect that the presence of a deposit insurance scheme has a differential influence on systemic risk. On the one hand, bank managers could be inclined to engage in more risk-taking thereby increasing the individual bank's contribution to systemic risk (see Yorulmazer,

26 In a recent study, Ongena et al. (in press) find lower barriers to entry and tighter restrictions on bank activities in domestic markets to be associated with lower bank lending standards not only in domestic markets, but also in foreign markets. 
2012). On the other hand, following the classic result of the Diamond and Dybvig (1983) model, the existence of deposit insurance should prevent bank runs and thus reduce systemic risk. To further characterize the moral hazard problem induced by the presence of deposit insurance, we also employ in our regressions the dummy variables Coverage per account and Permanent fund. While the former takes on the value one if deposit insurance coverage applies per account (and not per depositor), the latter takes on the value one if a permanent insurance fund exists and zero in case an explicit deposit insurance is implemented but no permanent fund exists.

Complementing these variables on the banks' regulatory environment, we also use several standard country controls from various data sources. We consider GDP growth (taken from the World Bank's World Development Indicator, WDI, Database) as a standard macroeconomic control variable. Also, we use the Anti-Director Rights Index proposed by La Porta et al. (1998) and revised by Diankov et al. (2008) and Spamann (2010) as well as the Anti-Self-Dealing Index proposed by Diankov et al. (2008) as two proxies for shareholder protection.27 Furthermore, we employ the Creditor Rights Index proposed by La Porta et al. (1998) and revised by Djankov et al. (2007), which measures the rights of creditors in case of a bankrupt bank being liquidated. Further, we also control for differences in the development of our sample countries' financial sectors. In particular, we use the variable Stock market turnover defined as total stock market volume as a percent of total shares outstanding from the WDI database as a proxy for the depth and liquidity of a country's equity market (see also Favara et al., forthcoming; Bartram et al., 2012). Everything else equal, our expectation regarding Stock market turnover is that banks operating in more developed financial markets should have better access to liquidity and funding and should thus contribute less to global systemic risk. One possible concern with our analysis of European and U.S. banks could be that our results on banks' systemic risk exposure and contribution are mechanically driven by the fact that the U.S. constitute a much larger part of the global stock market. Consequently, results from our regression analyses could be driven by this spurious composition effect rather than the systematic differences in bank characteristics and regulation. To address this concern, we also compute

$\overline{27} \quad$ As we find similar results for both indices, we only report the results for the ASDI in our regressions. 
each country's relative stock market importance in the world defined as a country's stock market turnover relative to the total worldwide stock market turnover. Finally, we use the variable Capital Account Openness taken from the database in Chinn and Ito (2008) to measure the financial openness of a country. Here, we expect the existence of cross-border capital account constraints to have an increasing effect on a bank's systemic risk contribution.

\subsection{Descriptive statistics}

Panel A of Table I presents mean estimates of our systemic risk measures and bank-specific variables for each country 28 In the last row of Panel A, we calculate the sample means across all countries. The mean annual buy-and-hold return of banks is minus $17.4 \%$. Our measure of bank performance varies widely across countries in our sample. For example, banks in emerging countries like Serbia, Slovenia or Ukraine have buy-and-hold returns of minus $63.6 \%$, minus $45.8 \%$ and minus $74.8 \%$, respectively. Bank performance in developed countries, on the other hand, is significantly better and varies from $5.7 \%$ in Sweden to only minus $10.7 \%$ in Germany. The average MES estimate in our full sample is $1.8 \%$.29 The average exposure of an individual bank to global systemic risk is highest for banks in the United Kingdom and lowest for Malta. The mean MES is higher for the U.S. than in 21 European countries. This simple comparison of mean MES estimates first hints at the possibility that U.S. banks could in general be more exposed to global systemic risk. Results on the dynamic MES support this view. While U.S. banks have a mean dynamic MES of 3.6\%, the average estimate across our full sample (regardless of whether we exclude U.S. banks) is only $2.3 \%$. This difference is highly economically significant. U.S. banks lost $1.3 \%$ more on their respective stocks than European banks during extreme downward movements of the global financial sector. Again, banks in the United Kingdom have the highest exposure to systemic risk on average with a mean dynamic MES of 5\%. Turning to the SRISK of banks in

28 We do not have data on our variables Liquidity beta and Performance for all bank-years in our sample. Thus, we do not report summary descriptives for these variables in Table I A similar note applies to our variables ADR, Liquidity and IFRS used later in our robustness checks.

29 This is in line with the estimates reported by Acharya et al. (2010) who find the MES of U.S. banks during the financial crisis to have ranged between $0.39 \%$ and 3.36\% (June 2006 to June 2007). 
our sample, we can see that this measure of a bank's combined liabilities and exposure to shocks in equity prices is highest for large developed European countries (e.g., France, Germany, United Kingdom) and significantly lower for U.S. banks. When interpreting the average SRISK, however, one has to keep in mind that our sample of U.S. banks includes considerably more bank-years from smaller banks. The results on the mean $\triangle \mathrm{CoVaR}$ estimates are inconclusive in this simple comparison across countries with U.S. banks contributing with the same magnitude to systemic risk as European banks. In unreported results, we also estimate the correlations between our three measures of systemic risk to address concerns that all three measures are indistinguishable. Correlations between the three measures range from $-43 \%$ to $34 \%$ for European and U.S. banks. We thus conclude that although all three measures are interconnected, they nevertheless measure distinct aspects of a bank's systemic relevance.

Panel A of Table \also provides country means for our bank-specific variables that we use for matching and as explanatory variables in our regressions. Mean bank size as measured by the banks' total assets ranges from \$ 1.2 billion for Latvia to $\$ 725.7$ billion in the United Kingdom. On average, U.S. banks have total assets of \$ 161.3 billion with banks from several European countries (Belgium, France, Germany, Spain, Sweden, United Kingdom) having higher mean total assets. Market-to-book ratios and leverage of U.S. banks do not significantly differ from the mean estimates for these two variables across all countries. In addition, the non-interest income to total interest income ratio of U.S. banks $(33.8 \%)$ is only slightly smaller than the average across our full sample (36.4\%). However, U.S. banks have considerably higher total loans to total assets ratios $(62.7 \%$ compared to $49.3 \%)$, higher loan loss provisions ( $\$ 129.8$ billion compared to $\$$ 78.8 billion) and smaller debt maturity (43.5\% compared to $89.8 \%$ ). Interestingly, U.S. banks are significantly less interconnected on average than banks in our full sample although we attribute this finding to the inclusion of several smaller U.S. banks in our sample.

Turning to the country-specific variables we employ in our regressions, Panel B of Table I] presents median estimates of these variables. Starting with the Capital Regulatory Index, values for this measure of the stringency of capital regulations vary widely across countries. Not surprisingly, 
values for the index are highest for the U.S. and large countries of the European Union like, e.g., the United Kingdom, France and Germany. Similarly, supervisory authorities are more independent in large developed European countries whereas values for our variable Independence of Supervisory Authority are lowest for emerging countries like, e.g., Bulgaria, Hungary and Serbia. The U.S. also has more powerful supervisory authorities than most emerging and smaller developed European countries. Next, we find a large variation of the coverage limit of deposit insurance schemes across the countries in our sample. The U.S. is at the lower-end of this range with a ratio of the coverage to GDP per capita of one, while countries like, e.g., Denmark, Italy and Norway have ratios well above four. Almost all countries in our sample have a deposit insurance that applies per depositor with the U.S. being one of only four countries where deposit insurance applies per account. With only few exceptions, all countries also have a permanent fund as part of their explicit deposit insurance scheme. GDP growth also varies widely, with emerging countries expectedly having higher growth rates than developed countries. Compared to most European countries, the U.S. has low creditor and medium shareholder rights. Finally, there is also large variation in the development status of national equity markets proxied by the measure for stock market turnover. The U.S. is in the top quintile of this measure with emerging markets having significantly lower values for Stock market turnover. As expected, the mean value for our variable Stock market importance is highest for the U.S.

\section{Do European and U.S. banks differ in their contribution to global systemic risk?}

In this section, we investigate the question whether U.S. banks destabilize the global financial system in a more pronounced fashion than European banks of equal size and valuation. First, we describe the procedure we use for matching European banks to U.S. banks using propensity scores. Second, we discuss the differences in systemic risk contribution of matched banks. 


\subsection{Matching European banks to U.S. banks}

We intend to analyze the marginal contribution to global systemic risk of comparable European and U.S. banks. Banks in Europe and the U.S. will naturally differ in their systemic importance due to simple differences in firm size and valuation. We thus employ a matching approach that attempts to match each European bank in our sample to a similar U.S. bank of similar size and valuation in each year. To be precise, we follow Drucker and Puri (2005), Bartram et al. (2011) and Bartram et al. (2012) and use propensity score (p-score) matching to compare banks along two dimensions simultaneously. We match European banks to U.S. banks based on firm size, proxied by the natural logarithm of a bank's total assets, and on a bank's market-to-book ratio as a proxy for the bank's valuation. The motivation behind the choice of these two bank characteristics for matching is evident. If a bank's marginal contribution to global systemic risk is only determined by its size and/or valuation, matching pairs of European and U.S. banks should not differ in their systemic relevance. Matching based on propensity scores is done by first estimating a logit regression of an indicator function of membership to the sample of U.S. banks on firm size and valuation. In the second step, European and U.S. banks are matched using the predicted values from the first step by minimizing the difference between the estimated propensity scores of European and U.S. banks following the "nearest neighbor" technique. For the propensity score matching to yield unbiased results, variables used for matching and systemic risk measures must not be determined simultaneously. To control for the possibility that firm size and valuation are determined at the same time as the banks' MES, we employ lagged values of total assets and market-to-book ratios. To improve the quality of our matching, European banks are matched to U.S. banks with replacement and matching is done for each year in our sample period. For increased transparency, we illustrate our matching procedure by listing the 50 largest matching banks in 2011 sorted by bank size in Table B.2]in the Appendix.

Table 凹presents a comparison of our bank- and country-specific variables for European banks and their matching U.S. peers. All variables are averages of the available bank-year observations we have for a given European bank and its matching U.S. bank(s). In Panel A of Table 凹, we 
compare the variables used in the matching procedure and the resulting propensity scores. The differences between the market-to-book ratios of European banks and matching U.S. banks are not statistically significant according to a t-test and significant only at the $10 \%$ level according to a Wilcoxon test. However, the U.S. banks in our sample are slightly larger than the European banks they are matched to. Nevertheless, the economic significance of the differences in mean and median total assets is small. Moreover, although the pairs of banks do not match perfectly with respect to both variables, the differences in the propensity scores based on both size and valuation are statistically insignificant. This result underlines the good quality of our matching of European to U.S. banks. We account for the fact that our matching of banks is imperfect with respect to bank size in two different manners. First, we include both the differences between bank size and valuation as additional explanatory variables in our regressions. Second, we perform an alternative matching using the procedure proposed by Almeida et al. (2012) which is based on the estimator of Abadie and Imbens (2006) in our robustness checks 30

Panel B of Table $\llbracket$ reports the results of our comparison of further bank-level characteristics. The differences in mean leverage are not statistically significant. However, European banks have both statistically and economically significantly higher median leverage than U.S. banks. European banks have mean non-interest income to total interest income ratios $(0.362)$ that are only marginally higher than those of their U.S. peers (0.320). Further, matching U.S. banks grant more loans relative to their total assets $(64.01 \%)$ than European banks $(50.12 \%)$. This difference is both statistically significant and economically large. Loan portfolios of U.S. banks are of significantly lower quality than those of European banks as evidenced by the higher loan loss provisions. Interestingly, mean and median values for our variable Debt maturity do not differ for European and U.S. banks. However, U.S. banks take significantly more deposits for their financing than European banks of equal size and valuation. We also compute but do not tabulate differences in liquidity betas and lagged buy-and-hold returns for European and U.S. banks for a smaller sample

$30 \quad$ We also perform an additional matching in which we only use total assets for matching and find that the results and conclusions from our main analysis remain unchanged. In fact, U.S. banks have a dynamic MES that is 129 basis points higher and an average $\Delta \mathrm{CoVaR}$ that is 90 basis points lower than corresponding mean values of European banks. 
of banks 31 In this smaller sample, U.S. have significantly higher buy-and-hold returns than European banks on average although both sample means have a negative sign. Liquidity betas are larger for U.S. banks with the difference being weakly statistically significant. Finally, the degree of interconnectedness of European banks seems to be significantly higher than for U.S. banks.

Panel C of Table $\amalg$ also presents differences in the country-specific variables for European banks and matching U.S. banks. On average, European banks are subject to less stringent capital requirements than their U.S. peers. Not surprisingly considering the fact that our sample includes several emerging countries, supervisory authorities in the U.S. are more independent and have more power to discipline banks. Moreover, equity market development in the U.S. is significantly higher than in the European countries with the global importance of the U.S. stock market also being higher. The U.S. is also more open to cross-border capital transactions than the average European country in our sample. Conversely, European countries have better creditor rights, higher deposit insurance coverage limits on average and deposit insurance that predominantly applies per depositor and not per account.

In summary, our analysis reveals that matched U.S. banks differ significantly with respect to several bank-level characteristics from European banks. The differences, however, are quite surprising at first sight. On average, U.S. banks have less leverage, more deposits and the same amount of non-interest income than European banks. The simple comparisons of explanatory variables, however, do not account for the fact that several of the bank-level characteristics are correlated. Moreover, the comparisons presented in Table $\llbracket$ do not give any insight into the differential contribution to global systemic risk of European and U.S. banks. Therefore, we turn next to a comparison of systemic risk measures for our matched sample and afterwards perform multiple Fama-MacBeth style regressions to investigate the driving factors of systemic risk differences.

$31 \quad$ As the estimation of both variables requires additional data beyond 1991, values for both variables are not available for our full sample. 


\subsection{Differences in the contribution to global systemic risk}

Table III presents mean and median values for our three measures of the systemic risk contribution of European banks and matching U.S. banks. We also report corresponding values for the annual buy-and-hold stock returns of banks so that we can comment on differences in the banks' stock performance. For every European bank to appear only once in this comparison, the annual values for each European bank and its matching U.S. bank(s) are averaged. Panel A reports the comparison of European and U.S. banks in our full sample. U.S. banks contribute more to global systemic risk than European banks. This result holds for all three measures of systemic risk we employ. On average, U.S. banks have a dynamic MES that is 132 basis points higher than those of European banks. This differenc is both statistically and economically significant. U.S. banks also contribute more to global systemic risk according to the estimates for $\Delta$ CoVaR and SRISK. In contrast, U.S. banks have higher mean buy-and-hold returns though both values are negative. While matching U.S. banks lost $12.33 \%$ on their stocks per year on average during our sample period, European banks had average annual buy-and-hold returns of minus 16.16\%. This difference is not statistically significant in a t-test. Yet, with the annual stock performance of European and U.S. banks differing by almost $4 \%$, this effect is economically large.

One could be concerned that the higher exposure and contribution of U.S. banks to global systemic risk we find are driven by a few banks in our sample that are particularly large. In fact, the evidence in our data points at the opposite result. In Figure 3 we plot histograms of the differences in the annual mean dynamic MES, $\triangle \mathrm{CoVaR}$ and SRISK between European and U.S. banks. As done throughout our study, differences are computed by subtracting the systemic risk measure of matched U.S. banks from the corresponding estimates of European banks. 32 The plots clearly show that apart from few outliers the majority of matched U.S. banks contribute more (and are also more exposed) to global systemic risk than European banks. Note that the individual

32 Negative differences in MES and SRISK thus indicate pairs of banks in which the matched U.S. banks have a higher exposure and contribution, respectively, to global systemic risk than the corresponding European banks they are matched to. Conversely, negative differences in $\triangle \mathrm{CoVaR}$ indicate a higher contribution of European banks to global systemic risk. 
absolute differences in SRISK shown in Panel C of Figure 3 are relatively small underlining the good quality of our matching procedure with respect to total assets and bank size.

In Panel B of Table III, we restrict our sample to bank-year observations from European banks from the EU 15. We thus exclude several emerging markets like, e.g., Latvia, Lithuania or Poland from this analysis. The dynamic MES of U.S. banks is again higher than the respective estimates for matching European banks. The difference in mean dynamic MES estimates is minus 163 basis points and thus even more pronounced for our sub-sample of banks in the EU 15 countries than for our full sample. The difference in the European and U.S. banks' SRISK estimates is large while the estimates for $\Delta \mathrm{CoVaR}$ are marginally smaller but still statistically significant. Interestingly, the higher systemic importance of U.S. banks is accompanied by significantly better stock performance (minus $7.55 \%$ ) compared to European banks (minus 17.16\%). Complementing our analysis of predominantly developed countries in the EU 15, Panel C of Table III provides a similar analysis of the sub-sample of other countries outside the EU 15. Banks in these countries have better stock performance on average, although the difference of $1.45 \%$ is not statistically significant. As expected, U.S. banks are more exposed to and also contribute more to global systemic risk than banks from emerging European countries. The difference between the mean dynamic MES of European and U.S. banks is minus 148 basis points and thus both statistically and economically significant. The results for $\Delta \mathrm{CoVaR}$ and SRISK are similar.

Figure 4 shows mean estimates of dynamic MES, SRISK and $\triangle$ CoVaR of European banks in excess of corresponding estimates for matching U.S. banks in our sample sorted by country. From Panel A we can see that banks from only few European countries are more exposed to global systemic risk than matching U.S. banks. Most notably, banks from the United Kingdom have higher average estimates for the dynamic MES than matching U.S. banks. A similar result can only be found for few emerging countries from eastern Europe and Belgium with most banks in these countries being considerably smaller than banks in the UK. This result is in line with our economic intuition given the importance of the UK (and London in particular) as a major global financial hub. This result is underlined by the results in Panel B in which we present the same 
sorting of countries for the SRISK estimates of European banks. Expect for banks in the UK, all European banks have an average SRISK that is either equal to or lower than the SRISK of their matching U.S. bank. Panel $\mathrm{C}$ shows further results on the differences in $\Delta$ CoVaR indicating a higher contribution to global systemic risk of matching U.S. banks on average. Our key result thus is that the higher global systemic importance of U.S. banks is a phenomenon common to all European countries with the exception of the United Kingdom. Differences between the average systemic risk measure estimates are largest for several smaller and/or emerging markets like, e.g., Cyprus, Malta and Turkey. However, U.S. banks also have a significantly higher exposure and contribution to global systemic risk than France, Germany or Italy.

In Table IV, we report the mean differences in annual buy-and-hold returns and our three measures of systemic risk contribution of European banks and matched U.S. banks by year. With the exception of 1997, differences in annual bank performance are statistically and economically significant in all years in our sample. European banks performed significantly better in the crisis year 2009 (61.5\% difference in performance), while U.S. banks consistently had better stock performance before and after 2009 (10.1\% to 29.7\% difference). Between 1999 and 2011, European banks had a higher exposure to to global systemic risk in only two years (2006 and 2010). U.S. banks had significantly higher dynamic MES values for most of the years in the 2000s. This finding also holds for SRISK with U.S. banks having a higher contribution to global systemic risk than European banks throughout our sample period. Results for $\Delta \mathrm{CoVaR}$ are also broadly in line with our key finding with U.S. banks having a higher contribution to global systemic risk in the majority of sample years (with 1999, 2006 and 2010 being the expection in the fifteen years). In 2009, at the climax of the financial crisis, U.S. banks had an unparalleled high mean dynamic MES that was $10.4 \%$ higher than corresponding mean estimates for European banks. The marginal exposure to global systemic risk also reached a peak in the year 2000, brought on by the LTCM crisis. During this year, U.S. banks had an annual mean dynamic MES that was 7.2\% higher than the respective mean dynamic MES of European banks. Results for the years before 1999 are mixed. Several annual mean estimates for our risk measures are not statistically significantly different from zero, 
and both MES and $\triangle \mathrm{CoVaR}$ only offer ambiguous results for the earliest years in our sample.

Panel A of Figure 5 further illustrates how the mean exposure of banks to global systemic risk evolves through our sample period. Two observations are noteworthy. First, the average exposure of U.S. banks to global systemic risk did not differ significantly from that of European banks until 1998. Starting with the enactment of the Gramm-Leach-Bliley Act and the introduction of the Euro, however, U.S. banks were more strongly exposed to global systemic risk than European banks 33 The mean marginal exposure of U.S. banks to global financial fragility after these events has a characteristic U-shape. Second, the mean dynamic MES estimates for U.S. banks peaked in the year 2000 as well as during the Subprime crisis. European banks, on the other hand, were not exposed to risk in the global financial system to such an extent. Therefore, one key observation from Figure 5 is that the higher systemic fragility of U.S. banks appears to be significantly more pronounced during episodes of financial crisis. Because of these findings, we later perform additional regressions in which we split our sample period in 2005 (start of the Subprime crisis) to control for structural breaks in our data. Panels B and C in Figure 5 present corresponding plots for SRISK and $\triangle$ CoVaR. As evidenced by the plot of the SRISK estimates, U.S. banks had a higher average contribution to global systemic risk than European banks throughout our sample period.

However, while the average SRISK of European banks increased steadily and almost in a linear fashion until the start of the financial crisis, the average contribution of U.S. banks to systemic risk peaked significantly at the end of the last millenium and in the years leading to the financial crisis. Interestingly, SRISK estimates of European banks increased sharply during the financial crisis. Finally, results for $\triangle \mathrm{CoVaR}$ shown in Figure 5 are mostly in line with our intuition. The average contribution to global systemic risk was regularly higher for U.S. banks in most sample years although several of these differences appear to be economically insignificant. U.S. banks, however, contributed significantly more to global systemic risk at the height of the financial crisis in 2008 and 2009 with European banks having a higher contribution to global systemic risk at the

33 While the Gramm-Leach-Bliley Act has been criticized by many commentators to have had a detrimental effect on systemic risk in the U.S., the introduction of the Euro could have had beneficial effects on financial stability in the European Union (e.g., due to the elimination of currency risks, better financial integration, etc.). 
start of the Euro crisis in 2010.

In summary, our analysis reveals that U.S. banks contribute significantly more to global systemic risk than comparable European banks. As we match banks based on the bank's total assets, these economically large differences across a variety of systemic risk measures cannot be explained by simple differences in firm size.

\section{Why do U.S. banks contribute more to global systemic risk?}

In this section, we investigate the determinants of the differences in banks' marginal exposure and contributions to global systemic risk. First, we present results of our baseline Fama-MacBeth style regressions of differences in dynamic MES, SRISK and $\triangle \mathrm{CoVaR}$. A brief discussion of robustness checks is given in the second part of this section.

\subsection{Which factors explain the differences in the contribution to global sys- temic risk?}

We now present the results of regressions that aim at answering the question which factors can explain the higher systemic importance of U.S. banks. The dependent variables in these regressions are the difference in annual mean dynamic MES, SRISK and $\triangle$ CoVaR between European banks and matching U.S. institutions. We regress these differences on differences in several bank- and country-specific explanatory variables in Fama-MacBeth style regressions. 34 As we employ a dependent variable that results from a first stage estimation, our regressions could suffer from heteroskedasticity and OLS will produce badly inconsistent standard error estimates. Therefore, standard errors are corrected for heteroskedasticity and possible autocorrelation following Newey and West (1987). To mitigate the problem that both the systemic risk measures and some of our regressors could be determined simultaneously, we lag all explanatory variables by one

$34 \quad$ Unreported results on our models' variance inflation factors confirm that our regressions do not suffer from multicollinearity. 
year 35 For an easy interpretation of the estimated regression coefficients, all explanatory variables are standardized to have zero mean and unit standard deviation in all regressions. An estimated coefficient thus represents the effect of a one standard deviation increase in the explanatory variable on the difference in the respective systemic risk measure allowing a quick grasp on the economic significance of each regressor.

Table $\mathrm{V}$ shows the results of our Fama-MacBeth regressions. Models (1) to (3) employ the differences in dynamic MES as the dependent variable with model (1) constituting our baseline regression estimated using our full sample of matched banks. Both variables used for matching European and U.S. banks are statistically insignificant in this specification thus underlining the high quality of our matching procedure. We find no consistent evidence that a bank's leverage or debt maturity are significantly correlated with its exposure to financial instability. In contrast, non-interest income enters regression (1) with a positive significant coefficient. This effect is economically significant as a one standard deviation increase in non-interest income increases the dynamic MES by 40 basis points. Banks that grant more loans are less exposed to global systemic risk as evidenced by the highly significant negative coefficient on our variable Loans. Our proxy for persistence in a bank's risk culture also enters regression (1) with a significant negative coefficient. The economic significance in both cases is large. A one standard deviation increase in the difference in the loans ratio decreases the difference in the annual dynamic MES by 20 basis points. An increase in the lagged buy-and-hold returns by one standard deviation leads to an even larger decrease of 50 basis points in the dynamic MES.

Turning to the country-specific variables, most of our variables that describe a country's regulatory environment and deposit insurance schemes do not enter regression (1) with a statistically significant coefficient. For example, we find no evidence pointing at the hypothesized negative relation between a bank's MES and a more independent supervisory authority. More stringent capital requirements are negatively correlated with a bank's systemic risk. Although the coefficient of the Capital Regulatory Index is not statistically significant, the effect of a one standard

35 In unreported model diagnostics, we also perform Breusch-Godfrey and Durbin-Watson tests on the OLS regressions in each sample year. The results show that our regressions do not suffer from autocorrelation. 
deviation increase in the index is nevertheless economically significant with the difference in the dynamic MES decreasing by 45 basis points. Furthermore, a one standard deviation increase in the index of the supervisory authority's power is associated with a decrease in the difference in a bank's annual dynamic MES by 20 basis points. Interestingly, the relation between the exposure to systemic risk and the variables concerning the existence of an explicit deposit insurance scheme is positive and economically significant. This result is in line with our theoretical predictions as a more extended coverage of depositors creates a moral hazard problem for banks. The coefficient of the Anti-Self-Dealing Index is positive and highly significant as well. In line with the arguments brought forward by John et al. (2008) that better investor protection leads to higher risk-taking by firms, we find shareholder protection to be positively associated with a bank's marginal exposure to systemic risk.

Regression (2) restricts our sample to bank-year observations of European banks with total assets in excess of $\$ 10$ billion. Again, both Total assets and the Market-to-book ratio do not enter this regression with a significant coefficient. The coefficient on the ratio of non-interest income to total interest income is positive and not statistically significant. The economic significance of the relation between non-interest income and a bank's systemic risk contribution, however, is even stronger for large banks than for our full sample. A one standard deviation increase in the noninterest income ratio is associated with an increase of $4.8 \%$ in MES. This coefficient provides further support for the hypothesis that stronger engagement in non-core activities outside of the traditional deposit taking and lending business increases a financial institution's exposure to turmoil in the global financial system. The loans to total assets ratio is no longer significant in this regression with the economic significance of this relation being small in comparison to the remaining explanatory variables. Surprisingly, Debt maturity enters regression (2) with a positive and highly economically significant coefficient. Consequently, we find no support for the findings of Gorton (2010) or Beltratti and Stulz (2012) that the funding fragility of banks is a critical driver of systemic risk. The coefficient on Performance is no longer significant in the regression for large banks. Most interestingly and in line with our expectation, the degree of a bank's interconnected- 
ness has high explanatory power for the variation in large banks' exposure to systemic risk. Again, we find that higher capital requirements and more powerful and independent supervision reduces a bank's exposure to systemic risk.

As illustrated by the plot in Panel A of Figure 5, the differences in mean dynamic MES between European and U.S. banks peaked during the crisis years of 2008 and 2009. Also, bank regulation and supervision were significantly adjusted during and after the financial crisis marking a significant regime change in our sample.

To investigate whether our results on the determinants of the differences in banks' marginal exposure to systemic risk also hold true in the time period during and after the financial crisis, we estimate regression (3) in which we exclude bank-year observations prior to 2006. Our previous findings based on our full sample remain mostly unchanged. Banks with more non-interest income, less granted loans and worse performance in the previous year were more exposure to global financial instability. Better shareholder protection, less stringent capital requirements and less strict supervision are all associated with banks having a higher systemic risk exposure.

In regressions (4) to (6), we repeat our regressions using the differences in the SRISK estimates of European and U.S. banks as the dependent variable. Again, model (4) constitutes our baseline regression based on our full sample of bank-year observations. Total assets enters this regression with a positive and highly statistically and economically significant coefficient. Supporting our previous findings from the regressions of MES, a higher non-interest income to interest income ratio and less traditional lending are associated with economically significant increases in a bank's contribution to systemic risk. In contrast to regression (1), however, we also find that a worse loan portfolio quality and a more fragile structure of the bank's funding all add to the systemic importance of a bank. Regression (4) also provides further support for the notion that more stringent capital requirements can help reduce the average systemic risk contribution of a bank. All remaining control variables are statistically insignificant in this model specification. In model (6), we only employ large banks in a regression of differences in SRISK. The signs of the coefficients on most variables remain unchanged although the validity of the statistical results is limited due 
to the small average sample size in this regression. Next, we repeat our regression of SRISK for the years during and after the financial crisis in specification (6). Several of our previous findings are even more pronounced in the crisis and post-crisis period with the economic significance of the coefficients of Loans and Loan loss provisions being larger than in our baseline regression. We also find SRISK to be negatively related to the Capital Regulatory Index and the index of the independence of the supervisory agency. Contrasting our findings for a bank's MES, the power of the supervisory agency is positively correlated with a bank's SRISK. Surprisingly, the existence of a permanent fund is negatively correlated with SRISK. Similar to the results on MES, we find the ASDI to be positively related to a bank's contribution to systemic risk.

Finally, columns (7) to (9) of Table $\mathrm{V}$ present the results of regressions of differences in $\Delta \mathrm{CoVaR}$. Total assets enters both the regression for the full sample as well as the regression for the crisis and post-crisis period with a significant negative sign showing a positive relation between bank size and systemic risk contribution. Apart from this somewhat expected finding, we find none of the bank-level characteristics to be a significant driver of $\Delta \mathrm{CoVaR}$. The only significant correlation we find is between the loans to total assets ratio and the $\Delta \mathrm{CoVaR}$ of large banks again underling the finding that more traditional loan lending decreases a bank's contribution to systemic risk. A more powerful supervisory agency decreases the average contribution of banks to systemic instability while an explicit deposit insurance scheme appears to help stabilize the financial system.

\subsection{Robustness checks}

Complementing the main regressions discussed in the previous subsection, we also investigate the robustness of our results using various different model specifications and additional data. 36

As a first robustness check, we employ an alternative procedure for matching European to U.S. banks. We follow Almeida et al. (2012) and Kahle and Stulz (in press) and match banks using the estimator of Abadie and Imbens (2006). In contrast to propensity score matching, this estimator

36 We do not tabulate the results of our robustness checks. The results are nevertheless available from the authors upon request. 
first computes the Mahalanobis distance between banks using total assets and the market-to-book ratio as covariates. In the second step, European banks in the treatment group are matched with U.S. banks in the control group by minimizing the Mahalanobis distances. The results of our matching remain unchanged with U.S. banks also contributing significantly more and being more exposed to global systemic risk than European banks in this alternative specification.

Additionally, we control for an imperfect matching with respect to bank size by repeating our p-score matching procedure using Total assets as the only matching variable. Naturally, the mean difference in size between matching banks vanishes in this alternative setting. However, our FamaMacBeth style regressions produce results that are qualitatively and quantitatively similar to those we find in our main analysis. It could also be criticized that our matching based on total assets and the market-to-book value does not account for differences in the business models of European and U.S. banks. To account for this, we perform an additional matching in which we include the non-interest income to interest income ratio as an additional matching variable. Our main findings remain qualitatively and quantitatively the same.

Next, it could be argued that our results are biased by differences in accounting standards across banks 37 Consequently, total assets of European banks using IFRS could be biased upwards and matched pairs of banks could significantly differ in their true size. We believe the biasing effect of differences in accounting standards on our conclusions to be negligible. First, if total assets of European banks were indeed overstated, differences in the systemic relevance of banks should be even larger in magnitude on account of the too-big-to-fail argument (thus further underlining our main finding). Second, we estimate regressions in which we include a variable which takes on integer values from one to 23 where one means that the bank states its balance sheets according to local standards and 23 that the bank uses IFRS 38 Again, our results are robust to these alternative model specifications. Next, we re-estimate our regressions using the ratio of total debt to total assets as an alternative measure of leverage. Our findings are unaffected and our conclusions

\footnotetext{
$37 \quad$ As noted by Beltratti and Stulz (2012), IFRS standards forced banks to report more assets than banks that reported results using U.S. GAAP in 2006 (e.g., due to stricter restrictions on keeping special purpose vehicles off balancesheet and in netting positions.)

38 Data on the accounting standards followed by the banks in our sample are taken from Worldscope.
} 
remain unchanged.

We also estimate regressions in which we include the Liquidity betas of the banks as a further explanatory variable to control for the banks' exposure to illiquid assets. 39 Similarly, we estimate additional regressions in which we use data on activity and entry restrictions for local banking sectors taken from the database of Barth et al. (2006, 2013). Our main results remain unchanged with none of these additional explanatory variables entering our regressions with a significant coefficient.

Furthermore, we control for a possible selection bias caused by the incomplete coverage of global stocks in the Worldscope and Datastream databases. For this purpose, we follow Bartram et al. (2012) and construct a variable labeled Market coverage for each country and year in our sample that captures the coverage of a country's equity market in Worldscope/Datastream. The number of listed companies that are available in Worldscope/Datastream are extracted manually by using the Explorer function in Datastream while data on the total number of listed companies in a country is taken from the websites of the World Federation of Exchanges and individual stock exchanges. In line with the findings of Hou et al. (2011), overall coverage of global equity markets in Datastream is near complete. Including Market coverage as a further control variable in our regressions does not change our findings as it enters all regressions with an insignificant coefficient.

We also check our results' robustness to a change in the index that is used for estimating our measures of a bank's contribution to systemic risk. To this end, we re-estimate the dynamic MES, SRISK as well as $\triangle$ CoVaR using the MSCI World Financials index as a proxy for the global financial sector portfolio. We find that our conclusions are unchanged.

Also, it could be argued that our results are primarily driven by the averaging of the daily dynamic MES. To control for such a possible bias, we consider the minimum as well as the maximum daily dynamic MES in a year as further dependent variables in our robustness checks. Again, our results are not affected and our conclusions remain unchanged.

One might be concerned that our results could be biased by the fact that some of the European

39 In a related study, Fahlenbrach et al. (2012) show that banks with higher exposure to illiquid assets are more likely to perform worse during times of crisis. 
banks in our sample also engage heavily in business in the U.S. Consequently, our findings could be driven by the inclusion of such multinational banks in our analysis. To control for such a confounding effect, we re-estimate our main regression (1) and include a dummy variable ADR which takes on the value one if a European bank has a U.S. cross-listing in the form of an American Depositary Receipt (ADR) program and zero otherwise. Fernandes and Ferreira (2008) find that such a cross-listing increases stock price informativeness in the form of idiosyncratic volatility especially in developed countries. In the context of banking, Ongena et al. (in press) show that stricter regulation in domestic markets is associated with lower bank lending standards abroad. In our setting, a U.S. cross-listing could thus be indicative of a European bank's stronger business ties with the U.S. leading to a higher contribution to global systemic risk. The ADR dummy variable enters this new regression with a significant positive coefficient. This result is consistent with our main finding. While U.S. banks, on average, are more systemically relevant than European banks, the cross-listing of a European bank increases its contribution to systemic risk relative to its matching U.S. bank. Put differently, differences in dynamic MES between European and U.S. banks lessen in case European banks enter the U.S. financial market. Moreover, we find that the estimates of the coefficients on our independent variables in this regression are not affected and our conclusions remain unchanged.

We also control for differences in the bank stocks' liquidity. As shown by Han and Lesmond (2011), estimates for a stock's beta factor can be significantly biased downwards if the stock is illiquid. The differences in systemic risk that we find could therefore be caused by the relative illiquidity of European banks' stocks in comparison with U.S. banks. In fact, we find that U.S. banks have stocks that are significantly more liquid on average than European banks. As a measure for an individual stock's liquidity, we use a variant of the Amihud measure as proposed by Karolyi et al. (2012). They adjust the Amihud measure of illiquidity by adding a constant and taking the natural logarithm of the original Amihud measure to minimize the effect of outliers. The resulting measure is multiplied by minus 1 to yield a measure that is increasing in the stock's liquidity. We then estimate a regression in which we include the annual mean of the daily adjusted 
Amihud measures as a further explanatory variable. The adjusted Amihud measure of liquidity is not significant in this regression and its inclusion does not change our conclusions.

Finally, both MES and $\triangle \mathrm{CoVaR}$ are solely based on market data and not accounting data. Although Acharya et al. (2010) note that MES is a significant driver of a bank's expected capital shortage conditional on an undercapitalization of the system, Brownlees and Engle (2012) argue that a dynamic reduced form approach to measuring the expected capital shortage should be preferred. Furthermore, measures that capture both leverage and downside risk of equity in a unified measure could be more appropriate to measure an individual bank's systemic risk contribution. However, as we additionally compute and compare estimates for the SRISK of European and U.S. banks in our analysis, we believe our results for both the MES and $\triangle$ CoVaR of U.S. banks to be robust to such an alternative measure of systemic risk.

\section{Conclusion}

In this paper, we document that U.S. banks are more exposed and contribute significantly more to global systemic risk than European banks. Our key result is that U.S. banks, on average, have an annual MES, SRISK and $\triangle \mathrm{CoVaR}$ that are all significantly higher than the corresponding mean estimates of European banks of matching size and valuation. This result is both statistically and economically significant and particularly pronounced during (though not limited to) the aftermath of the LTCM and Subprime crises. As we match European banks to U.S. banks based on their total assets and firm valuation, the differences that we find in the banks' systemic relevance cannot be explained by simple differences in bank size. We then investigate why the marginal exposure and contribution to systemic risk is significantly higher for matching U.S. banks than for European banks. We find the exposure of banks to financial instability to be increasing in the bank's non-interest income and decreasing in its loans-to-assets ratio as well as its performance in previous years. Banks that engage more in non-traditional banking and less in traditional lending are thus more sensitive to adverse effects in a financial crisis. Furthermore, we find that the degree 
of interconnectedness of a bank with the global financial system only drives the systemic risk exposure of large banks. Differences in systemic risk exposure are also driven by country-specific factors. Most notably, we find more stringent capital requirements and a higher independence of a country's supervisory agency to decrease a bank's exposure to systemic risk. The former result should be of particular interest to policymakers as our results confirm results of the recent study by Berger and Bouwman (2013) who show that bank capital increases a bank's survival probability. Complementing their result, we find that higher capital requirements have indeed been effective in the crisis and post-crisis era in reducing banks' average exposure and contribution to systemic risk. Results for the SRISK and the $\triangle \mathrm{CoVaR}$ underline these findings. Finally, in line with a positive correlation between investor protection and corporate risk-taking, we find better shareholder rights to increase a bank's exposure and contribution to global financial fragility.

We find no evidence in support of comments that hypothesize the funding fragility of banks to be a key driver of global systemic risk. Additionally, more stringent capital requirements for banks appear to have been particularly effective after the crisis based on our results using the SRISK metric that incorporates data on a bank's capital structure.

A word of caution is in order when interpreting our results, however. Although our evidence shows that U.S. banks, on average, contribute more to global systemic risk than comparable European banks, we do not investigate the question to what extent these countries' financial sectors as a whole destabilize the global financial system. Even if the mean contribution of banks to global systemic risk in a country is low, the country's financial sector as a whole could still have a significant impact on global financial stability. Furthermore, our analysis mainly addresses hypotheses on the determinants of systemic risk that go beyond the traditional too-big-to-fail discussion. Larger banks will indubitably contribute more to global systemic risk than smaller ones. Our evidence shows, however, that several other idiosyncratic factors besides bank size as well as countryspecific characteristics have an economically large effect on a bank's exposure and contribution to systemic risk. 


\section{A Appendix: Systemic risk measures}

This appendix provides the technical details of the methods used for estimating the different measures of systemic risk used in the empirical study.

\section{A.1 Marginal Expected Shortfall}

Let $R=\sum_{j} y_{j} R_{j}$ be a bank's return where $R_{j}$ is the return of the $j^{\text {th }}$ firm group or trading desk and $y_{j}$ is the weight of group $j$ in the bank's total portfolio. Next, the bank's Expected Shortfall $E S$ is defined as

$$
E S_{\alpha}=-\mathbb{E}\left[R \mid R \leq-V A R_{\alpha}\right]=-\sum_{j} y_{j} \mathbb{E}\left[R_{i} \mid R \leq-V a R_{\alpha}\right]
$$

where $\operatorname{VaR}_{\alpha}$ is the Value-at-Risk with confidence level $1-\alpha$, which is defined as $\operatorname{Pr}(R<-\operatorname{VaR})=$ $\alpha$. Thus, the ES is the expected loss conditional on the loss being greater than the $\operatorname{VaR}_{\alpha}$. Acharya et al. (2010) define group j's Marginal Expected Shortfall MES ${ }^{j}$ as the sensitivity of the bank's overall risk to the exposure $y_{j}$ to each group $j$ :

$$
M E S_{\alpha}^{j}=\frac{\partial E S_{\alpha}}{\partial y_{j}}=-\mathbb{E}\left[R_{j} \mid R \leq-V A R_{\alpha}\right] .
$$

Therefore, the MES measures how group j's risk taking adds to the bank's overall risk and the MES can be calculated by estimating group $j$ 's losses conditional on the firm as a whole doing poorly.

Assuming systemic events to be extreme tail events that are characterized by the market experciencing its worst $p \%$ outcomes at daily frequency, the bank's Marginal Expected Shortfall is then defined as

$$
\operatorname{MES}_{p \%}^{j}=\mathbb{E}\left[\frac{w_{1}^{j}}{w_{0}^{j}}-1 \mid I_{p \%}\right]
$$

where $\frac{w_{1}^{j}}{w_{0}^{i}}-1$ are the net equity returns of bank $j$ during the bad market outcomes and $I_{p \%}$ is an 
indicator variable for the market return being in its left $p \%$-tail. The static MES is then simply computed as the average return on any given bank $\left(R_{b}\right)$ conditional on the market (or sector) return being in the $p \%$ left tail:

$$
\operatorname{MES}_{p \%}^{b}=\frac{1}{\# \text { days }} \sum_{\text {system is in } p \% \text { tail }} R_{b, t} .
$$

\section{A.2 Dynamic Marginal Expected Shortfall}

Addressing concerns that the static definition of the MES proposed by Acharya et al. (2010) cannot adequately capture the time variation in a bank's exposure to systemic risk, Brownlees and Engle (2012) propose a dynamic specification that builds on well-known time series techniques. Therefore, let $R_{j, t}$ and $R_{M, t}$ be the $j^{t h}$ bank's and the market log return on day $t$, respectively. The bivariate process of the daily bank and market returns is then given by

$$
\begin{aligned}
R_{M, t} & =\sigma_{M, t} \epsilon_{M, t}^{1} \\
R_{j, t} & =\sigma_{j, t} \rho_{j, t} \epsilon_{M, t}^{2}+\sigma_{M, t} \sqrt{1-\left(\rho_{j, t}\right)^{2}} \epsilon_{j, t}^{2} \\
\left(\epsilon_{M, t}^{1}, \epsilon_{j, t}^{2}\right) & \sim H,
\end{aligned}
$$

where $\sigma_{i, t}$ is the conditional volatility of the market return $(i=m)$ or bank $j$ 's return $(i=j), \rho_{j, t}$ is the conditional market/bank correlation and $\left(\epsilon_{M, t}^{1}, \epsilon_{j, t}^{2}\right)$ are i.i.d. innovations with $\mathbb{E}\left(\epsilon_{i, t}^{j}\right)=0$, $\operatorname{Var}\left(\epsilon_{i, t}^{j}\right)=1$ for $n=\{1,2\}$ and $i=\{j, M\}$ and zero covariance (although they are not necessarily independent of each other).

The one-period-ahead MES for a systemic event $S$ is denoted by

$$
\begin{aligned}
M E S_{j, t-1}^{1} & =\mathbb{E}_{t-1}\left(R_{j, t} \mid R_{M, t}<S\right) \\
& =\sigma_{j, t} \mathbb{E}_{t-1}\left(\rho_{j, t} \epsilon_{M, t}^{1}+\sqrt{1-\left(\rho_{j, t}\right)^{2}} \epsilon_{j, t}^{2} \mid S / \sigma_{M, t}\right) \\
& =\sigma_{j, t} \rho_{j, t} \mathbb{E}_{t-1}\left(\epsilon_{M, t}^{1} \mid S / \sigma_{M, t}\right)+\sigma_{j, t} \sqrt{1-\left(\rho_{j, t}\right)^{2}} \mathbb{E}_{t-1}\left(\epsilon_{j, t}^{2} \mid S / \sigma_{M, t}\right) .
\end{aligned}
$$


Furthermore, the conditional probability of the systemic event is given by

$$
\operatorname{Pr}_{S, t}^{1}(S)=\operatorname{Pr}_{t-1}\left(r_{M, t}<S\right)=\operatorname{Pr}\left(\epsilon_{M, t}^{1}<S / \sigma_{M, t}\right) .
$$

In contrast to the one-period-ahead MES, the multi-period-ahead MES is estimated by a simulation procedure to construct forecasts. First, $K$ return paths of length $h$ for $k=1, \ldots, K$ are simulated on day $t-1$

$$
\left\{\begin{array}{l}
R_{M, t+\delta-1}^{k} \\
R_{j, t+\delta-1}^{k}
\end{array}\right\}_{\delta=1}^{h} .
$$

Next, pseudo-innovations are drawn from the innovation distribution $H$ yielding

$$
\left(\epsilon_{M, t+\delta-1}^{1, k}, \epsilon_{M, t+\delta-1}^{2}\right)_{\delta=1}^{h} \sim H .
$$

Using the pseudo-innovations in the Dynamic Conditional Correlation (DCC) and GARCH models with the current levels of volatility and correlation as starting conditions, we obtain the simulated return paths. The MES is then estimated as the Monte Carlo average of the simulated paths

$$
M E S_{j, t-1}^{h}(S)=\frac{\sum_{k=1}^{K} R_{j, t: t+h-1}^{k} I\left\{R_{M, t: t+h-1}^{k}<S\right\}}{\sum_{k=1}^{K} I\left\{R_{M, t: t+h-1}^{k}<S\right\}},
$$

where $R_{i, t: t+h-1}^{k}$ is the $k^{\text {th }}$ simulated cumulative return of bank $j$ or of the market from period $t$ to period $t+h-1$, i.e.,

$$
R_{j, t: t+h-1}^{k}=\exp \left\{\sum_{\delta=1}^{h} r_{j, t: t+h-1}^{k}\right\}-1 .
$$

Finally, the multi-period probability of a crisis is then given by

$$
\operatorname{Pr}_{S, t}^{1}(S)=\operatorname{Pr}_{t-1}\left(R_{M, t: t+h-1}^{k}<S\right)=\frac{1}{K} \sum_{k=1}^{K} I\left\{R_{M, t: t+h-1}^{k}<S\right\} .
$$

We follow Brownlees and Engle (2012) and consider the 6-months period MES as the "long term" 
or "long run" MES of a bank.

\section{A.3 $\Delta$ CoVaR}

The $\operatorname{CoVaR} \alpha_{\alpha}^{j l i}$ of institution $j$ (or the financial system) is defined as the Value-at-Risk (VaR) given by $\operatorname{Pr}\left(R_{i} \leq \operatorname{VaR} R_{\alpha}^{i}\right)=\alpha$ conditional on some event $\mathbb{C}\left(R_{i}\right)$ of institution $i$, where $R_{i}$ is the return of institution $i$ for which the $V a R_{\alpha}^{i}$ is defined. The $C o V a R_{\alpha}^{j l i}$ is implicitly defined by the $\alpha$-quantile of the conditional probability distribution:

$$
\operatorname{Pr}\left(R_{j} \leq \operatorname{CoVaR} R_{\alpha}^{j \mid \mathbb{C}\left(R_{i}\right)} \mid \mathbb{C}\left(R_{i}\right)\right)=\alpha
$$

Then, the contribution of institution $i$ to the $\mathrm{VaR}$ of institution $j$ (or the financial system) is denoted by

$$
\Delta \operatorname{CoVaR}_{\alpha}^{j \mid \mathbb{C}\left(R_{i}\right)}=\operatorname{CoVaR} R_{\alpha}^{j \mid R_{i}=\operatorname{VaR}_{\alpha}^{i}}-\operatorname{CoVaR}_{\alpha}^{j \mid R_{i}=\operatorname{Median}^{i}}
$$

To measure an individual bank's contribution to systemic risk, $j$ is simply set to be the financial sector. Hence, $\triangle \operatorname{CoVaR} R_{\alpha}^{j \mid \mathbb{C}\left(R_{i}\right)}$ or simply $\triangle \operatorname{CoVaR}{ }_{\alpha}^{i}$ denotes the difference between the financial system's VaR conditional on a particular financial institution $i$ being in distress and the VaR of the financial system conditional on the median state of the institution $i$.

The constant or unconditional $C o V a R$ is estimated by quantile regressions. Let $\hat{R}_{q}^{\text {system,j }}$ be the predicted value of a quantile regression of the financial sector on a particular institution or portfolio $i$ for the $q^{\text {th }}$-quantile:

$$
\hat{R}_{q}^{s y s t e m, j}=\hat{\alpha}_{q}^{j}+\hat{\beta}_{q}^{j} \hat{R}_{q}^{j},
$$

where $\hat{R}_{q}^{\text {system,j }}$ is the predicted value for a particular quantile conditional on institution $j$. Now, the VaR of the financial system conditional on $R^{j}, V a R_{q}^{s y s t e m} \mid R^{j}$, is the predicted value of the quantile regression of the system on institution $j, \hat{R}_{q}^{s y s t e m, j}$, because $V a R_{q}^{s y s t e m} \mid R^{j}$ is the conditional quantile, i.e.,

$$
\operatorname{VaR}_{q}^{\text {system }} \mid R^{j}=\hat{R}_{q}^{\text {system, }},
$$


If $R^{j}=V a R_{q}^{i}$, then the $C o V a R$ measure conditioned on the event $\left\{R^{j}=V a R_{q}^{j}\right\}$ is

$$
\operatorname{CoVaR} R_{q}^{\text {system } \mid R^{j}=\operatorname{VaR}_{q}^{j}}:=\operatorname{VaR}_{q}^{\text {system }} \mid \operatorname{VaR} R_{q}^{j}=\hat{\alpha}_{q}^{j}+\hat{\beta}_{q}^{j} \operatorname{VaR}_{q}^{j}
$$

and the $\triangle \operatorname{CoVaR} R_{q}^{j}$ is

$$
\Delta \operatorname{CoVaR} R_{q}^{j}=\operatorname{VaR} R_{q}^{s y s t e m \mid j}=\hat{\beta}_{q}^{j}\left(\operatorname{VaR} R_{q}^{j}-V a R_{50 \%}^{j}\right) .
$$

Then, assume that the returns $R_{i, t}$ have the linear factor structure

$$
R_{j, t}=\phi_{0}+M_{t-1} \phi_{1}+R_{i, t} \phi_{2}+\left(\phi_{3}+M_{t-1} \phi_{4}+R_{i, t} \phi_{5}\right) \epsilon_{t}^{i}
$$

with $M_{t-1}$ as a vector of state variables. Furthermore, the i.i.d. error term $\epsilon_{t}$ with zero mean and unit variance is independent of $M_{t-1}$ so that $\mathbb{E}\left[\epsilon_{t}^{j} \mid M_{t-1}, R_{i, t}\right]=0$. The returns are generated by a "location scale" process, therefore the conditional expected return $\mathbb{E}\left[R_{j, t} \mid M_{t-1}, R_{i, t}\right]=\phi_{0}+$ $M_{t-1} \phi_{1}+R_{i, t} \phi_{2}$ and the conditional volatility $\operatorname{Var}_{t-1}\left[X_{t}^{j} \mid M_{t-1}, R_{i, t}\right]=\phi_{3}+M_{t-1} \phi_{4}+R_{i, t} \phi_{5}$ are dependent on the set of state variables $M_{t-1}$ and on $R_{i, t}$. The quantile regressions include estimates of the conditional mean and the conditional volatility for generating conditional quantiles. The model is estimated by these method for different percentiles. The cumulative distribution function (cdf) of $\epsilon^{j}$ is defined by $F_{\epsilon^{j}}\left(\epsilon^{j}\right)$ and its inverse cdf by $F_{\epsilon^{j}}^{-1}(q)$ for percentile $q$ with the conditional quantile function

$$
F_{R_{j, t}}^{-1}\left(q \mid M_{t-1}, R_{i, t}\right)=\alpha_{q}+M_{t-1} \gamma_{q}+R_{i, t} \beta_{q}
$$

where $\alpha_{q}=\phi_{0}+\phi_{3} F_{\epsilon^{j}}^{-1}(q), \gamma_{q}=\phi_{1}+\phi_{4} F_{\epsilon^{j}}^{-1}(q)$ and $\beta_{q}=\phi_{2}+\phi_{5} F_{\epsilon^{j}}^{-1}(q)$ for quantiles $q \in(0,1)$. Now, we have

$$
\operatorname{VaR}_{q}^{j}=\inf _{\operatorname{VaR}_{q}}\left\{\operatorname{Pr}\left(R_{t} \leq \operatorname{VaR}_{q} \mid M_{t-1}, R_{i, t}\right) \geq q\right\}=F_{R_{j, t}^{-1}}^{-1}\left(q \mid M_{t-1}, R_{i, t}\right)
$$


and by conditioning on $X_{t}^{i}=V a R_{q}^{i}$ we get the $\mathrm{CoVaR}_{q}^{j \mid i}$ by

$$
\operatorname{CoVaR} R_{q}^{j \mid i}=\inf _{\operatorname{VaR}_{q}}\left\{\operatorname{Pr}\left(R_{t} \leq \operatorname{VaR}_{q} \mid M_{t-1}, R_{i, t}=\operatorname{VaR}_{q}^{i}\right) \geq q\right\}=F_{R_{j, t}}^{-1}\left(q \mid M_{t-1}, \operatorname{VaR} R_{q}^{i}\right)
$$

Here, the quantile function is estimated as the predicted value of the $q$-quantile regression of $R_{i, t}$ on $M_{t-1}$ and $R_{j, t}$ by solving

$$
\min _{\alpha_{q}, \beta_{q}, \gamma_{q}} \sum_{t} \begin{cases}q\left|R_{j, t}-\alpha_{q}-M_{t-1} \gamma_{q}-R_{i, t} \beta_{q}\right|, & \text { if }\left(R_{j, t}-\alpha_{q}-M_{t-1} \gamma_{q}-R_{i, t} \beta_{q}\right) \geq 0 \\ (1-q)\left|R_{j, t}-\alpha_{q}-M_{t-1} \gamma_{q}-R_{i, t} \beta_{q}\right|, & \text { if }\left(R_{j, t}-\alpha_{q}-M_{t-1} \gamma_{q}-R_{i, t} \beta_{q}\right)<0 .\end{cases}
$$

Next, we outline the estimation of the conditional CoVaR, i.e., CoVaR $\mathrm{Con}_{t}$ and $\mathrm{VaR}_{t}$ are timevarying and we estimate the time variation conditional on a vector of lagged state variables $M_{t-1}$. They can be interpreted as conditioning variables shifting the conditional mean and the conditional volatility of the risk measures. The previous quantile regression is now performed using weekly data with

$$
\begin{aligned}
R_{i, t} & =\alpha^{i}+\gamma^{i} M_{t-1}+\epsilon_{t}^{i} \\
R_{\text {system }, t} & =\alpha^{\text {system } \mid i}+\beta^{\text {system } \mid i} R_{i, t}+\gamma^{\text {system } \mid i} M_{t-1}+\epsilon^{\text {system } \mid i}
\end{aligned}
$$

The predicted values of VaR and CoVaR are given by

$$
\begin{aligned}
\operatorname{VaR}_{t}^{i}(q) & =\hat{\alpha}^{i}+\hat{\gamma}^{i} M_{t-1} \\
\operatorname{CoVaR}_{t}^{i}(q) & =\hat{\alpha}^{\text {system } \mid i}+\hat{\beta}^{\text {system } \mid i} \operatorname{VaR}_{t}^{i}(q)+\hat{\gamma}^{\text {system|i }} M_{t-1} .
\end{aligned}
$$

Here the predicted values from the regressions of $R_{i, t}$ and $R_{\text {system }, t}$ are used. In the end, $\Delta \mathrm{CoVaR}_{t}^{i}$ 
for each institution is calculated by

$$
\begin{aligned}
\Delta \operatorname{CoVaR}_{t}^{i}(q) & =\operatorname{CoVaR}_{t}^{i}(q)-\operatorname{CoVaR}{ }_{t}^{i}(50 \%), \\
& =\hat{\beta}^{\text {system|i }}\left(\operatorname{VaR}_{t}^{i}(q)+\operatorname{VaR}_{t}^{i}(50 \%)\right) .
\end{aligned}
$$

In our study, both the unconditional and conditional CoVaR are estimated using the change in the three-month Treasury bill rate, the difference between the ten-year Treasury Bond and the three-month Treasury bill rate, the change in the credit spread between BAA-rated bonds and the Treasury bill rate, the return on the Case-Shiller Home Price Index, and implied equity market volatility from VIX as state variables.

\section{A.4 SRISK}

To incorporate data on the sensitivity of a bank's equity to crises together with information on the bank's liabilities in a unified framework, Acharya et al. (2012) and Brownlees and Engle (2012) propose SRIS K which is defined as

$$
\text { SRIS } K_{j, t}=\mathbb{E}_{t-1}\left(\text { Capital Shortfall }{ }_{j} \mid \text { Crisis }\right) .
$$

It describes the expected need for capital of bank $j$ in case of a financial crisis. The SRISK for bank $i$ at time $t$ is then estimated using the specification

$$
\operatorname{SRISK}_{i, t}=k\left(\text { Debt }_{i, t}\right)-(1-k)\left(1-\text { LRMES }_{i, t}\right) \text { Equity }_{i, t}
$$

where $k$ is set to $8 \%$ to denote the regulatory capital ratio, $D e b t_{i, t}$ is the bank's book value of debt, $L R M E S_{i, t}$ is the long term or long run Marginal Expected Shortfall proxied by $1-\exp (-18$. dynMES ), dynMES is the dynamically estimated MES and Equity ${ }_{i, t}$ is the banks's market value of equity. 


\section{B Appendix: Additional tables}




\section{Table B.1: Variable definitions and data sources.}

The appendix presents definitions as well as data sources for all dependent and independent variables that are used in the empirical study. The bank characteristics were retrieved from the Thomson Reuters Financial Datastream and Thomson Worldscope databases. The country control variables are taken from the World Bank's World Development Indicator (WDI) database. Data on the banks' regulatory environment and deposit insurance schemes are taken from Barth et al. (2006), Barth et al. (2013) and Demirgüc-Kunt et al. (2008), respectively.

\begin{tabular}{|c|c|}
\hline Variable name & Definition \\
\hline \multicolumn{2}{|l|}{ Dependent variables } \\
\hline Buy-and-hold returns & Annual buy-and-hold stock returns computed from the first and last trading day in a year. \\
\hline MES & $\begin{array}{l}\text { Annual Marginal Expected Shortfall as defined by Acharya et al. }(2010) \text { as the average } \\
\text { return on an individual bank's stock on the days the World Datastream Bank index expe- } \\
\text { rienced its } 5 \% \text { worst outcomes. }\end{array}$ \\
\hline Dynamic MES & $\begin{array}{l}\text { Dynamic Marginal Expected Shortfall as defined by Acharya et al. (2010) and calculated } \\
\text { following the procedure laid out by Brownlees and Engle (2012). }\end{array}$ \\
\hline$\Delta \mathrm{CoVaR}$ & $\begin{array}{l}\text { Conditional } \triangle \mathrm{CoVaR} \text { as defined by Adrian and Brunnermeies }(2011) \text {, measured as the dif- } \\
\text { ference between the Value-at-Risk (VaR) of a country-specific financial sector index con- } \\
\text { ditional on the distress of a particular bank and the VaR of the sector index conditional } \\
\text { on the median state of the bank. As state variables for the computation of conditional } \\
\Delta \mathrm{CoVaR} \text {, we employ the change in the three-month Treasury bill rate, the difference be- } \\
\text { tween the ten-year Treasury Bond and the three-month Treasury bill rate, the change in } \\
\text { the credit spread between BAA-rated bonds and the Treasury bill rate, the return on the } \\
\text { Case-Shiller Home Price Index, and implied equity market volatility from VIX. }\end{array}$ \\
\hline SRISK & 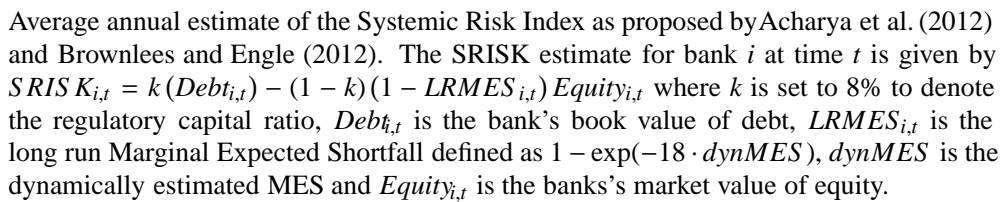 \\
\hline
\end{tabular}

Bank characteristics Total assets

Market-to-book

Leverage

Non-interest income

Loans

Loan loss provisions

Debt maturity

Deposits

Performance
Natural logarithm of a bank's total assets at fiscal year end.

Market value of common equity divided by book value of common equity.

Book value of assets minus book value of equity plus market value of equity, divided by market value of equity (see Acharya et al, 2010).

Non-interest income divided by total interest income.

Ratio of total loans to total assets

Natural logarithm of expenses set aside as an allowance for uncollectable or troubled loans.

Total long-term debt (due in more than one year) divided by total debt.

Total deposits divided by total liabilities.

Buy-and-hold returns of a bank lagged by one year.
Data source

Datastream, own. calc.

Datastream, own. calc.

Datastream, own. calc.

Datastream, Chicago

Board Options Exchange Market, Federal Reserve Board's H.15, S\&P, own. calc.

Datastream, own. calc.

Worldscope (WC02999).

Worldscope (WC07210 and WC03501).

Worldscope (WC02999, WC03501, WC08001), own calc.

Worldscope (WC01021 and WC01016).

Worldscope (WC02271 and WC02999).

Worldscope (WC01271).

Worldscope (WC03251 and WC03255).

Worldscope (WC03019 and WC03351).

Datastream, own. calc. 


\section{Table B.1: Variable definitions and data sources. (continued)}

\begin{tabular}{|c|c|c|}
\hline Variable name & Definition & Data source \\
\hline Interconnectedness & 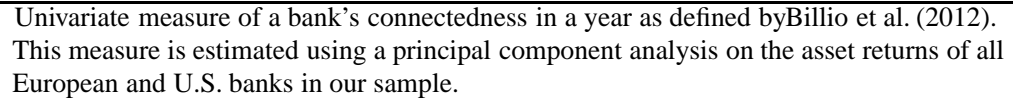 & Datastream, own calc. \\
\hline Liquidity beta & $\begin{array}{l}\text { The beta factor of a bank in year } t \text { with respect to liquidity innovations as defined by } \\
\text { Pástor and Stambaugh (2003) using a regression of monthly stock returns in excess of } \\
\text { the three-month Treasury bill rate during the years } t-3 \text { to } t-1 \text { on the excess returns of } \\
\text { country-specific market indexes and liquidity innovations. }\end{array}$ & Datastream, own calc. \\
\hline ADR & $\begin{array}{l}\text { Dummy variable that takes on the value one if a European bank has a U.S. cross-listing in } \\
\text { the form of an American Depositary Receipt (ADR) program and zero otherwise. }\end{array}$ & Datastream, own calc. \\
\hline Liquidity & $\begin{array}{l}\text { Amihud measure of an individual stock's illiquidity adjusted following the proce- } \\
\text { dure proposed by Karolyi et al. (2012). The adjusted Amihud measure is defined as } \\
-\ln \left(1+\frac{\left|R_{i, t}\right|}{P_{i, t} V O_{i, t}}\right) \text { where } R_{i, t} \text { is the return, } P_{i, t} \text { is the price and } V O_{i, t} \text { is the trading vol- } \\
\text { ume of stock } i \text { on day } t \text {. }\end{array}$ & Datastream, own calc. \\
\hline IFRS & $\begin{array}{l}\text { Takes on integer values from one to } 23 \text { where one means that the bank states its balance } \\
\text { sheets according to local standards and } 23 \text { that the bank uses IFRS. }\end{array}$ & Worldscope (WC07536) \\
\hline \multicolumn{3}{|l|}{ Regulatory environment } \\
\hline Capital Regulatory Index & $\begin{array}{l}\text { Index of the stringency of capital regulations in the banking system, capturing whether the } \\
\text { capital requirement reflects certain risk elements and deducts certain market value losses } \\
\text { from capital before minimum capital adequacy is determined. Index ranges from } 0 \text { to } 10 \text {. } \\
\text { Higher values denote greater stringency. }\end{array}$ & Barth et al. 2006, 2013). \\
\hline $\begin{array}{l}\text { Independence of Supervi- } \\
\text { sory Authority }\end{array}$ & $\begin{array}{l}\text { Index of the degree to which the supervisory authority is independent of the executive } \\
\text { branch of government. Index ranges from } 0 \text { to } 3 \text {. Higher scores denote greater indepen- } \\
\text { dence. }\end{array}$ & Barth et al. 2006, 2013). \\
\hline Supervisory & $\begin{array}{l}\text { Index of the extent to which supervisory authorities have the authority to discipline banks } \\
\text { by taking specific actions to prevent and correct problems. Index ranges from } 0 \text { to } 14 \text {. } \\
\text { Higher scores denote greater power. }\end{array}$ & Barth et al. 2006, 2013). \\
\hline Restrictions & $\begin{array}{l}\text { Index of the overall restrictions on bank activities that measures the extent to which a bank } \\
\text { can both engage in securities, insurance, and real estate activities and own nonfinancial } \\
\text { firms. Index ranges from } 4 \text { to } 16 \text {. Higher scores denote greater restrictiveness. }\end{array}$ & Barth et al. 2006, 2013). \\
\hline Private monitoring index & $\begin{array}{l}\text { Index of the incentives and capabilities provided by regulatory and supervisory authorities } \\
\text { to encourage the private monitoring of banks. Index ranges from } 0 \text { to } 12 \text {. Higher scores } \\
\text { indicate greater regulatory empowerment of the monitoring of banks by private investors. }\end{array}$ & Barth et al. 2006, 2013). \\
\hline Coverage limit & $\begin{array}{l}\text { Coverage limit of deposit insurance scheme in local currency divided by GDP per capita. } \\
\text { Missing for countries with full coverage. }\end{array}$ & $\begin{array}{l}\text { Demirgüc-Kunt et al. } \\
\text { (2008). }\end{array}$ \\
\hline Coverage per account & $\begin{array}{l}\text { Dummy variable that equals one if deposit insurance coverage applies per account, and } \\
\text { zero if coverage applies per depositor. }\end{array}$ & $\begin{array}{l}\text { Demirgüc-Kunt et al } \\
\text { (2008). }\end{array}$ \\
\hline Permanent fund & $\begin{array}{l}\text { Dummy variable that equals zero if an explicit deposit insurance schemes but no perma- } \\
\text { nent fund exists, one if a permanent fund exists, and missing otherwise. }\end{array}$ & $\begin{array}{l}\text { Demirgüc-Kunt et al. } \\
\text { (2008). }\end{array}$ \\
\hline
\end{tabular}


Table B.1: Variable definitions and data sources. (continued)

\begin{tabular}{|c|c|c|}
\hline Variable name & Definition & Data source \\
\hline $\begin{array}{l}\text { Country characteristics } \\
\text { GDP growth }\end{array}$ & Annual real GDP growth rate (in \%). & WDI database. \\
\hline $\begin{array}{l}\text { Anti-Director Rights In- } \\
\text { dex }\end{array}$ & $\begin{array}{l}\text { Anti-Director Rights Index of La Porta et al. }(1998) \text { as revised by Diankov et al }(2008) \\
\text { and Spamann }(2010) \text {. The ADRI takes values from } 0 \text { to } 5 \text { with a higher value meaning } \\
\text { better shareholder rights. }\end{array}$ & Spamann 2010). \\
\hline Anti-Self-Dealing Index & $\begin{array}{l}\text { Anti-Self-Dealing Index of Diankov et al. }(2008) \text {. Higher values of the ASDI indicate } \\
\text { better legal protection of minority shareholders against expropriation by corporate insid- } \\
\text { ers. }\end{array}$ & Diankov et al. (2008). \\
\hline Creditor Rights Index & $\begin{array}{l}\text { Index that aggregates creditor rights following La Porta et al. (1998) and Diankov et al. } \\
\text { (2007). The index ranges from } 0 \text { (weak creditor rights) to } 4 \text { (strong creditor rights). }\end{array}$ & Diankov et al. (2007). \\
\hline Stock market turnover & Ratio of annual trading volume to shares outstanding. & WDI database. \\
\hline Stock market importance & $\begin{array}{l}\text { Ratio of the stock market turnover of country } i \text { to the worldwide stock market turnover } \\
\text { (computed as the sum over all countries in the WDI database). }\end{array}$ & WDI database. \\
\hline Capital account openness & $\begin{array}{l}\text { Index of the financial openness of a country as proposed by Chinn and Ito (2008). A } \\
\text { higher index value implies stronger restrictions on cross-border capital transactions. }\end{array}$ & Chinn and Itd (2008). \\
\hline Market coverage & $\begin{array}{l}\text { Percentage of all locally listed firms in a country that are covered in the World- } \\
\text { scope/Datastream databases. }\end{array}$ & $\begin{array}{l}\text { Datastream, World Fed- } \\
\text { eration of Exchanges, } \\
\text { national stock exchange } \\
\text { websites, own calc. }\end{array}$ \\
\hline
\end{tabular}


Table B.2: Matched sample banks.

The appendix exemplifies the results of the matching procedure by listing the names of the first 50 European banks sorted by total assets in 2010 and their matching U.S. banks. Together with the bank names, the banks' respective total assets and market-to-book ratios used in propensity score matching are shown. Bank names are retrieved from the Worldscope database (item WC06001). Total assets are given in billion U.S. dollars.

\begin{tabular}{|c|c|c|c|c|c|}
\hline $\begin{array}{l}\text { Total } \\
\text { assets }\end{array}$ & $\begin{array}{l}\text { Market- } \\
\text { to-book }\end{array}$ & European bank & $\begin{array}{l}\text { Total } \\
\text { assets }\end{array}$ & $\begin{array}{l}\text { Market- } \\
\text { to-book }\end{array}$ & Matching U.S. bank \\
\hline $2,853.52$ & 0.89 & BNP PARIBAS & $2,117.61$ & 0.98 & JP MORGAN CHASE \& CO. \\
\hline $2,722.06$ & 0.63 & DEUTSCHE BANK & $2,117.61$ & 0.98 & JP MORGAN CHASE \& CO. \\
\hline $2,545.49$ & 1.30 & HSBC HDG. & $2,117.61$ & 0.98 & JP MORGAN CHASE \& CO. \\
\hline $2,401.49$ & 0.62 & BARCLAYS & $2,117.61$ & 0.98 & JP MORGAN CHASE \& CO. \\
\hline $2,337.01$ & 0.41 & ROYAL BANK OF SCTL.GP. & $2,264.91$ & 0.62 & BANK OF AMERICA \\
\hline $2,278.77$ & 0.63 & CREDIT AGRICOLE & $2,264.91$ & 0.62 & BANK OF AMERICA \\
\hline $1,722.25$ & 1.27 & BANCO SANTANDER & $1,913.90$ & 0.58 & CITIGROUP \\
\hline $1,617.22$ & 0.78 & SOCIETE GENERALE & $1,913.90$ & 0.58 & CITIGROUP \\
\hline $1,594.52$ & 0.70 & LLOYDS BANKING GROUP & $1,258.13$ & 1.17 & WELLS FARGO \& CO \\
\hline $1,265.07$ & 1.22 & UBS & $1,258.13$ & 1.17 & WELLS FARGO \& CO \\
\hline $1,077.08$ & 0.25 & COMMERZBANK & $1,258.13$ & 1.17 & WELLS FARGO \& CO \\
\hline 989.23 & 1.82 & CREDIT SUISSE GROUP N & $1,258.13$ & 1.17 & WELLS FARGO \& CO \\
\hline 809.21 & 0.88 & DEXIA & $1,258.13$ & 1.17 & WELLS FARGO \& CO \\
\hline 785.08 & 1.33 & BBV.ARGENTARIA & $1,258.13$ & 1.17 & WELLS FARGO \& CO \\
\hline 730.92 & 1.34 & NORDEA BANK & $1,258.13$ & 1.17 & WELLS FARGO \& CO \\
\hline 652.29 & 0.63 & NATIXIS & $1,258.13$ & 1.17 & WELLS FARGO \& CO \\
\hline 619.37 & 0.79 & DANSKE BANK & 307.79 & 1.56 & US BANCORP \\
\hline 533.70 & 1.30 & STANDARD CHARTERED & 307.79 & 1.56 & US BANCORP \\
\hline 456.89 & 0.60 & KBC GROUP & 307.79 & 1.56 & US BANCORP \\
\hline 346.15 & 0.46 & $\mathrm{CIC}$ & 307.79 & 1.56 & US BANCORP \\
\hline 344.57 & 0.48 & BANCA MONTE DEI PASCHI & 307.79 & 1.56 & US BANCORP \\
\hline 322.10 & 0.92 & DNB NOR & 307.79 & 1.56 & US BANCORP \\
\hline 307.51 & 0.89 & DEUTSCHE POSTBANK & 307.79 & 1.56 & US BANCORP \\
\hline 305.05 & 0.98 & SEB & 307.79 & 1.56 & US BANCORP \\
\hline 301.56 & 1.44 & SVENSKA HANDBKN. & 307.79 & 1.56 & US BANCORP \\
\hline 294.86 & 0.83 & ERSTE GROUP BANK & 264.28 & 0.82 & PNC FINL.SVS.GP. \\
\hline 284.39 & 1.84 & SBERBANK OF RUSSIA & 307.79 & 1.56 & US BANCORP \\
\hline 264.65 & -0.33 & SCHWEIZERISCHE NAT.BK. & 156.23 & 1.06 & $\mathrm{BB} \& \mathrm{~T}$ \\
\hline 240.12 & 0.86 & SWEDBANK & 264.28 & 0.82 & PNC FINL.SVS.GP. \\
\hline 238.66 & 0.18 & BANK OF IRELAND & 156.23 & 1.06 & $\mathrm{BB} \& \mathrm{~T}$ \\
\hline 204.93 & 0.31 & ALLIED IRISH BANKS & 156.23 & 1.06 & $\mathrm{BB} \& \mathrm{~T}$ \\
\hline 198.91 & 0.23 & BANK OF GREECE & 156.23 & 1.06 & $\mathrm{BB} \& \mathrm{~T}$ \\
\hline 190.45 & 0.29 & BANCO POPOLARE & 156.23 & 1.06 & $\mathrm{BB} \& \mathrm{~T}$ \\
\hline 187.60 & 1.23 & LANDESBANK BL.HLDG. & 264.28 & 0.82 & PNC FINL.SVS.GP. \\
\hline 187.53 & 0.89 & RAIFFEISEN BANK INTL. & 156.23 & 1.06 & $\mathrm{BB} \& \mathrm{~T}$ \\
\hline 185.77 & 0.58 & UBI BANCA & 156.23 & 1.06 & $\mathrm{BB} \& \mathrm{~T}$ \\
\hline 185.36 & 0.83 & BANCO POPULAR ESPANOL & 156.23 & 1.06 & $\mathrm{BB} \& \mathrm{~T}$ \\
\hline 172.56 & 1.23 & NATIONAL BK.OF GREECE & 156.23 & 1.06 & $\mathrm{BB} \& \mathrm{~T}$ \\
\hline 171.55 & 1.08 & BANCO ESPANOL DE CREDITO & 156.23 & 1.06 & $\mathrm{BB} \& \mathrm{~T}$ \\
\hline 142.50 & 0.69 & BANCO COMR.PORTUGUES & 132.35 & 0.47 & REGIONS FINL.NEW \\
\hline 137.99 & 0.82 & BANCO DE SABADELL & 132.35 & 0.47 & REGIONS FINL.NEW \\
\hline 124.37 & 1.05 & EFG EUROBANK ERGASIAS & 132.35 & 0.47 & REGIONS FINL.NEW \\
\hline 124.35 & 0.76 & ESPIRITO SANTO FINL.GP. & 132.35 & 0.47 & REGIONS FINL.NEW \\
\hline 119.61 & 0.84 & BANCO ESPIRITO SANTO & 132.35 & 0.47 & REGIONS FINL.NEW \\
\hline 108.86 & 1.06 & MEDIOBANCA & 111.01 & 0.76 & FIFTH THIRD BANCORP \\
\hline 107.17 & 0.11 & BANQUE NALE.DE BELGIQUE & 91.41 & 0.59 & KEYCORP \\
\hline 99.64 & 0.15 & CAJA DE AHORROS DEL MEDITERRANEO & 91.41 & 0.59 & KEYCORP \\
\hline 95.22 & 1.03 & ALPHA BANK & 111.01 & 0.76 & FIFTH THIRD BANCORP \\
\hline 90.41 & 1.59 & TKI.GARANTI BKSI. & 111.01 & 0.76 & FIFTH THIRD BANCORP \\
\hline 87.23 & 1.09 & TURKIYE IS BANKASI & 91.41 & 0.59 & KEYCORP \\
\hline
\end{tabular}




\section{References}

Abadie, A. And G. Imbens (2006): "Large Sample Properties of Matching Estimators for Average Treatment Effects,” Econometrica, 74, 235-267.

Acharya, V. V., Y. Aminud, AND L. Litov (2011): “Creditor rights and corporate risk-taking," Journal of Financial Economics, 101(1), 150-166.

Acharya, V. V., R. F. Engle, and M. Richardson (2012): "Capital Shortfall: A New Approach to Ranking and Regulating Systemic Risks," American Economic Review, 102(3), 59-64.

Acharya, V. V., L. H. Pedersen, T. Philippon, and M. Richardson (2010): "Measuring Systemic Risk," Working paper, New York University.

Acharya, V. V. and S. Steffen (2012): "Analyzing Systemic Risk of the European Banking Sector," in Handbook on Systemic Risk, ed. by J.-P. Fouque and J. Langsam, Cambridge University Press.

Acharya, V. V. and T. Yorulmazer (2008): "Cash-in-the-market pricing and optimal resolution of bank failures," Review of Financial Studies, 21(6), 2705-2742.

Adrian, T. and M. K. Brunnermeier (2011): “CoVaR,” Federal Reserve Bank of New York Staff Reports 348.

Adrian, T. AND H. S. Shin (2010): "Market Liquidity and Funding Liquidity," Journal of Financial Intermediation, 19(3), 418-437.

Almeida, H., M. Campello, B. Laranjeira, and S. Weisbenner (2012): "Corporate debt maturity and the real effects of the 2007 financial crisis," Critical Finance Review, 1, 3-58.

BAELE, L. (2005): "Volatility spillover effects in European equity markets," Journal of Financial Economics and Quantitative Analysis, 40(2), 373-401.

Barth, J. R., G. CAPrio, JR., ANd R. Levine (2004): "Bank regulation and supervision: What works best?” Journal of Financial Intermediation, 13, 205-248.

—_ (2006): Rethinking Bank Regulation: Till Angels Govern, Cambridge University Press, 1 ed.

(2013): "Bank Regulation and Supervision in 180 Countries from 1999 to 2011," NBER Working Paper No. 18733.

Bartram, S. M., G. W. Brown, and J. Conrad (2011): “The Effects of Derivatives on Firm Risk and Value," Journal of Financial and Quantitative Analysis, 46(4), 967-999.

Bartram, S. M., G. W. Brown, And J. E. Hund (2007): "Estimating Systemic Risk in the International Financial System," Journal of Financial Economics, 86, 835-869.

Bartram, S. M., G. W. Brown, and R. M. Stulz (2012): "Why Are U.S. Stocks More Volatile?" Journal of Finance, 67(4), 1329-1370. 
Basel Committee on Banking Supervision (2013): "Global systemically important banks: updated assessment methodology and the higher loss absorbency requirement," Tech. rep., Bank for International Settlements.

Bekaert, G., M. Ehrmann, M. Fratzscher, and A. J. Mehl (2012): “Global crises and equity market contagion," NBER Working Paper No. 17121.

Bekaert, G. and C. R. Harvey (1997): “Emerging equity market volatility,” Journal of Financial Economics, 43, 29-77.

613.

(2000): “Foreign speculators and emerging equity markets," Journal of Finance, 55, 565-

Beltratti, A. and R. M. Stulz (2012): “The Credit Crisis around the Globe: Why did some Banks perform better?" Journal of Financial Economics, 105, 1-17.

Benoit, S., G. Colletaz, C. Hurlin, and C. Pérignon (2013): "A Theoretical and Empirical Comparison of Systemic Risk Measures,” Working Paper.

Berger, A. N. and E. Bonaccorsi di Patti (2006): "Capital structure and firm performance: a new approach to testing agency theory and an application to the banking industry," Journal of Banking and Finance, 30, 1065-1102.

Berger, A. N. and C. H. Bouwman (2013): "How does capital affect bank performance during financial crises?" Journal of Financial Economics, 109, 146-176.

Billio, M., A. W. Lo, M. Getmansky, and L. Pelizzon (2012): "Econometric Measures of Connectedness and Systemic Risk in the Finance and Insurance Sectors," Journal of Financial Economics, 104(3), 535-559.

Black, L., R. Correa, X. Huang, and H. Zhou (2012): “The Systemic Risk of European Banks during the Financial and Sovereign Debt Crises," Working Paper.

Brownlees, C. T. and R. Engle (2012): "Volatility, Correlation and Tails for Systemic Risk Measurement," Working Paper.

Brunnermeier, M. K., G. Dong, and D. Palia (2012): “Banks' Non-Interest Income and Systemic Risk," Working paper, Princeton University.

Brunnermeier, M. K. and L. H. Pedersen (2009): "Market Liquidity and Funding Liquidity," Review of Financial Studies, 22, 2201-2238.

Buch, C. M. And G. DeLong (2008): "Do weak supervisory systems encourage bank risk taking?" Journal of Financial Stability, 4, 23-39.

Chinn, M. D. And H. Ito (2008): “A new Measure of Financial Openness,” Journal of Comparative Policy Analysis, 10, 307-320.

Cummins, J. D. And M. A. Weiss (2010): “Systemic Risk and the U.S. Insurance Sector,” Working paper, Temple University. 
De Jonghe, O. (2010): "Back to the Basics in Banking? A Micro-Analysis of Banking System Stability," Journal of Financial Intermediation, 19, 387-417.

De Nicolò, G. And M. Kwast (2002): "Systemic Risk and Financial Consolidation: Are they related?" Journal of Banking and Finance, 26, 861-880.

Demirgüç-Kunt, A. and E. Detragiache (2002): "Does deposit insurance increase banking system stability? An empirical investigation," Journal of Monetary Economics, 49, 1373-1406.

Demirgüç-Kunt, A., E. J. Kane, and L. Laeven (2008): “Determinants of deposit-insurance adoption and design," Journal of Financial Intermediation, 17, 407-438.

DeYoung, R. And G. Torna (in press): "Nontraditional banking activities and bank failures during the financial crisis," Journal of Financial Intermediation.

Diamond, D. W. And P. H. Dybvig (1983): “Bank Runs, Deposit Insurance, and Liquidity,” Journal of Political Economy, 91, 401-419.

Diamond, D. W. and R. G. Rajan (2009): “The credit crisis: Conjectures about causes and remedies," American Economic Review, 99, 606-610.

Duankov, S., R. La Porta, F. Lopez-de Silanes, and A. Schleifer (2008): “The Law and Economics of Self-Dealing," Journal of Financial Economics, 88, 430-465.

Duankov, S., C. McLiesh, and A. Shleifer (2007): "Private credit in 120 countries," Journal of Financial Economics, 84, 299-329.

Drucker, S. ANd M. Puri (2005): "On the benefits of concurrent lending and underwriting," Journal of Finance, 60(6), 2763-2799.

EnGLE, R. (2002): "Dynamic conditional correlation: A simple class of multivariate generalized autoregressive conditional heteroskedasticity models," Journal of Business and Economic Statistics, 20(3), 339-350.

Fahlenbrach, R., R. Prilmeier, and R. M. Stulz (2012): “This Time is the Same: Using Bank Performance in 1998 to Explain Bank Performance During the Recent Financial Crisis,' Journal of Finance, 67, 2139-2185.

Favara, G., E. Schroth, and P. Valta (forthcoming): "Strategic Default and Equity Risk Across Countries," Journal of Finance.

Fernandes, N. AND M. Ferreira (2008): "Does international cross-listing improve the information environment?" Journal of Financial Economics, 88, 216-244.

Foos, D., L. Norden, And M. Weber (2010): "Loan growth and riskiness of banks," Journal of Banking and Finance, 34, 2929-2940.

Gandhi, P. And H. Lustig (forthcoming): “Size Anomalies in U.S. Bank Stock Returns,” Journal of Finance. 
Giglio, S., B. Kelly, S. Pruitt, and X. Qiao (2013): "Systemic Risk and the Macroeconomy: An Empirical Evaluation,” Discussion Paper, The University of Chicago, Booth School of Business.

Gorton, G. (2010): Slapped by the invisible hand, Oxford University Press, 1 ed.

Group of Ten (2001): "Report on Consolidation in the Financial Sector," Tech. rep., Bank for International Settlements.

Han, Y. and D. Lesmond (2011): "Liquidity Biases and the Pricing of Cross-sectional Idiosyncratic Volatility," Review of Financial Studies, 24(5), 1590-1629.

Hautsch, N., J. Schaumburg, and M. Schienle (2012): "Financial Network Systemic Risk Contributions," Discussion Paper 2012-053, CRC 649, Humboldt-Universität zu Berlin.

Hou, K., G. A. Karolyi, and B.-C. Кно (2011): "What Factors Drive Global Stock Returns?" Review of Financial Studies, 24(8), 2527-2574.

Hovakimian, A., E. Kane, and L. Laeven (2012): "Variation in Systemic Risk at US Banks During 1974-2010,” NBER Working Paper No. 18043.

Huang, X., H. Zhou, and H. Zhu (2011): “Systemic Risk Contribution,” Finance and Economics Discussion Series, board of Governors of the Federal Reserve System.

Ince, O. And R. Porter (2006): "Individual Equity Return Data From Thomson Datastream: Handle With Care!” Journal of Financial Research, 29, 463-479.

John, K., L. Litov, And B. Yeung (2008): “Corporate governance and risk-taking,” Journal of Finance, 63, 1679-1728.

Jorion, P. and G. Zhang (2007): "Good and bad credit contagion: Evidence from credit default swaps," Journal of Financial Economics, 84(3), 860-883.

Kahle, K. M. and R. M. Stulz (in press): "Access to capital, investment, and the financial crisis," Journal of Financial Economics.

Karolyi, G. A., K.-H. Lee, and M. van DiJK (2012): "Understanding commonality in liquidity around the World," Journal of Financial Economics, 105(1), 82-112.

Keeley, M. C. (1990): “Deposit Insurance, Risk, and Market Power in Banking," American Economic Review, 80, 1183-1200.

La Porta, R., F. L. de Silanes, A. Shleifer, and R. Vishny (1998): “Law and Finance,” Journal of Political Economy, 106, 1113-1155.

Laeven, L. And R. Levine (2009): "Bank governance, regulation, and risk taking," Journal of Financial Economics, 93, 259-275.

Matutes, C. And X. Vives (2000): “Imperfect Competition, Risk Taking, and Regulation in Banking," European Economic Review, 44, 1-34. 
Merton, R. C. (1977): "An Analytical Derivation of the Cost of Deposit Insurance and Loan Guarantees: An Application of Modern Option Pricing Theory," Journal of Banking and Finance, 1, $3-11$.

Michelacci, C. AND F. Schivardi (forthcoming): “Does idiosyncratic business risk matter?” Journal of the European Economic Association.

Newey, W. and K. West (1987): "A simple, positive semi-definite, heteroskedasticity and autocorrelation consistent covariance matrix," Econometrica, 55, 703-708.

O’Hara, M. and W. Shaw (1990): "Deposit Insurance and Wealth Effects: The Value of Being "Too Big to Fail"," Journal of Finance, 45 (5), 1587-1600.

Ongena, S., A. Popov, And G. F. Udell (in press): ““When the cat's away the mice will play”: Does regulation at home affect bank risk-taking abroad?" Journal of Financial Economics.

Pástor, L. and R. F. Stambaugh (2003): “Liquidity risk and expected stock returns,” Journal of Political Economy, 111, 642-685.

Rabemananjara, R. AND J.-M. ZaKoÏAN (1993): "Threshold ARCH models and asymmetries in volatility," Journal of Applied Econometrics, 8, 31-49.

Schaeck, K., M. Činák, A. Maechler, and S. Stolz (2012): "Who Disciplines Bank Managers?" Review of Finance, 12, 197-243.

SchwaAb, B., S.-J. Koopman, and A. Lucas (2011): "Systemic risk diagnostics, coincident indicators and early warning signals," Technical report.

Shleifer, A. AND R. Vishny (2010): “Unstable Banking," Journal of Financial Economics, 97, 306-318.

Song, F. And A. Thakor (2007): "Relationship Banking, Fragility, and the Asset-Liability Matching Problem," Review of Financial Studies, 6, 2129-2177.

Spamann, H. (2010): “The “Antidirector Rights Index" Revisited," Review of Financial Studies, 23, $467-486$.

Stiglitz, J. E. (2010): Freefall: America, free markets, and the sinking of the world economy, W.W. Norton \& Company, Inc.

Stulz, R. M. (1999): “Globalization, corporate finance, and the cost of capital," Journal of Applied Corporate Finance, 12, 8-25.

(2005): “The limits of financial globalization,” Journal of Finance, 60, 1595-1638.

WAGNER, W. (2010): "Diversification at financial institutions and systemic crises," Journal of Financial Intermediation, 19, 373-386.

White, H., T.-H. Kim, and S. Manganelli (2012): "VAR for VaR: Measuring Tail Dependence Using Multivariate Regression Quantiles,” European Central Bank Working Paper. 
Yorulmazer, T. (2012): "Has Financial Innovation Made the World Riskier? CDS, Regulatory Arbitrage and Systemic Risk," Working Paper. 


\section{Figures and Tables}

Figure 1: Performance of European and U.S. banks, 1980-2011

This figure plots the performance of U.S. banks against the performance of European bank between 01-01-1980 and 12-31-2011. The plots are based on the US DS Banks and EUROPE DS Banks (Price) indexes retrieved from Thomson Reuters Financial Datastream. Both indexes are normalized to 100 at the start of the sample.

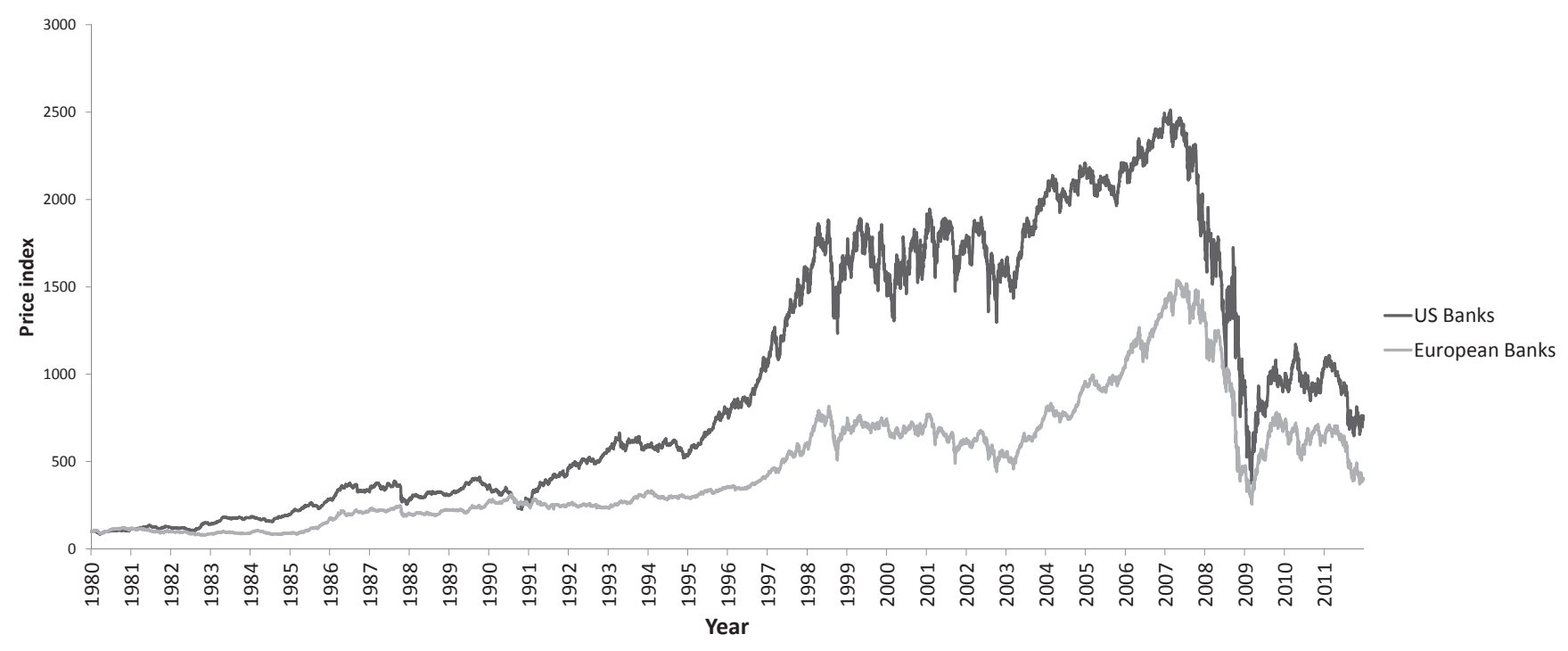


Figure 2: Bank-years in sample sorted by country, 1991-2011

This figure shows the total number of bank-years of European banks matched to U.S. banks in our sample sorted by country.

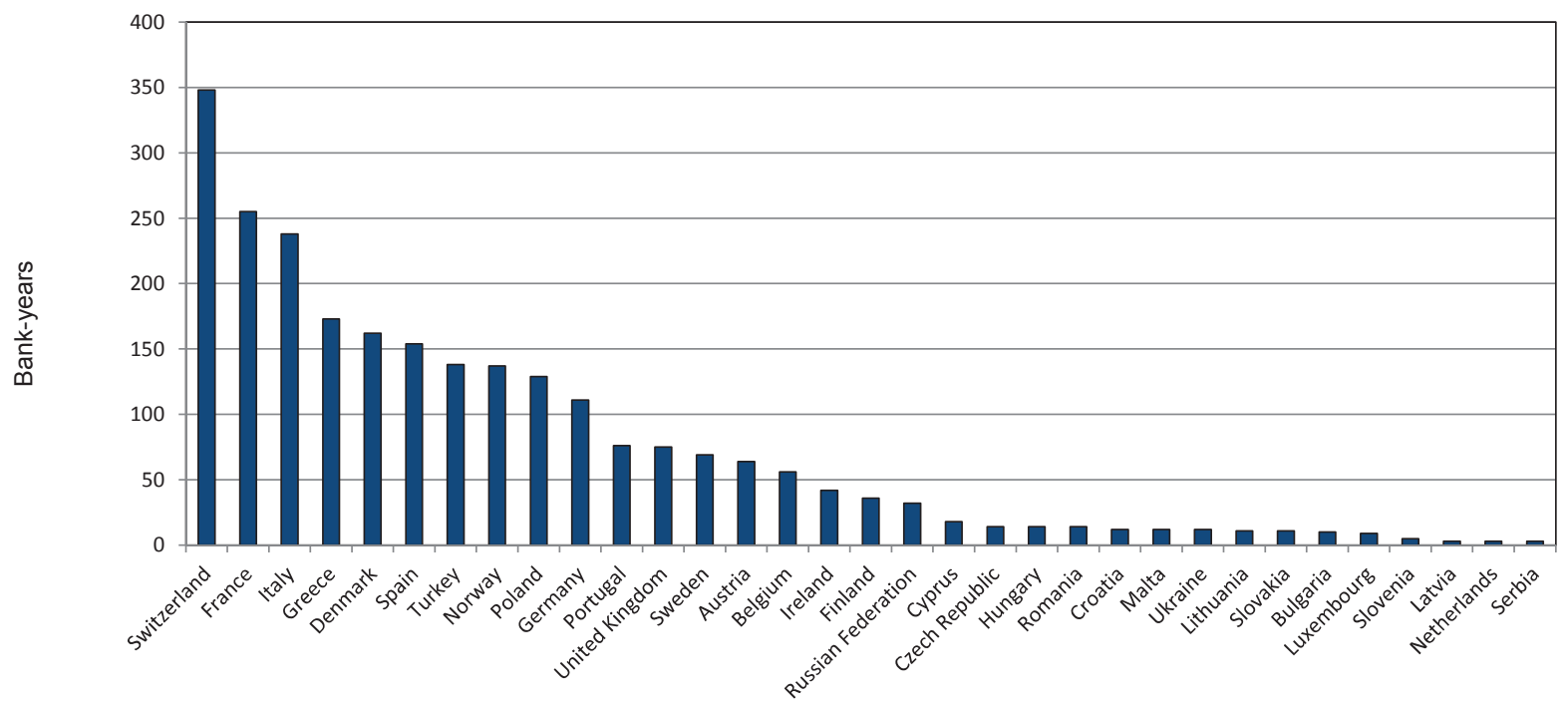




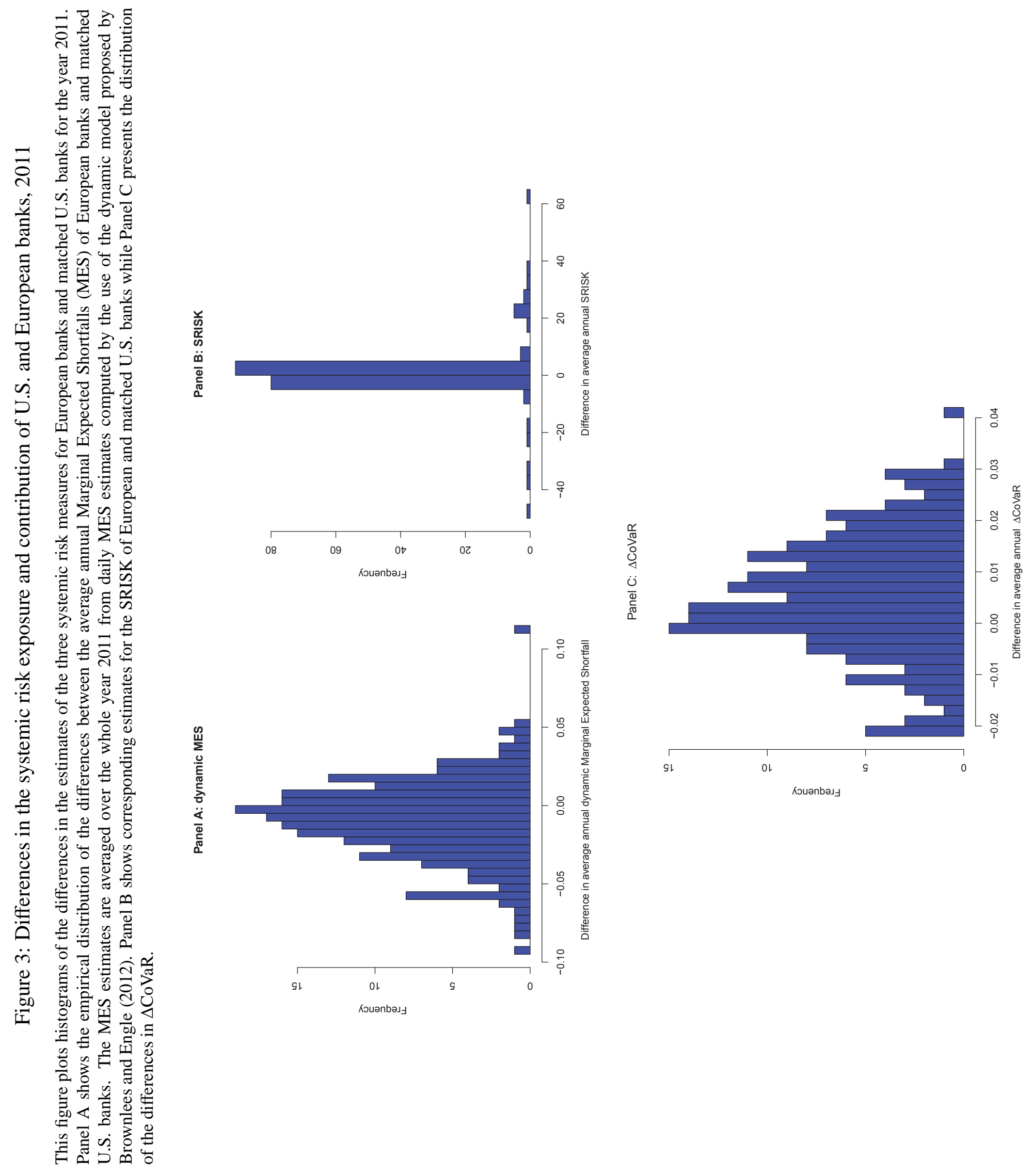


Figure 4: Systemic risk exposure of European banks sorted by country, 1991-2011

This figure shows average estimates of the three systemic risk measures of European banks in excess of the corresponding systemic risk measure estimates of matched U.S. banks in our sample sorted by country. Panel A shows the differences between the average annual Marginal Expected Shortfalls (MES) of European banks and matched U.S. banks. Panel B shows corresponding estimates for the SRISK of European and matched U.S. banks while Panel C presents the results of a comparison of $\Delta \mathrm{CoVaR}$ estimates across countries.

Panel A: Dynamic MES

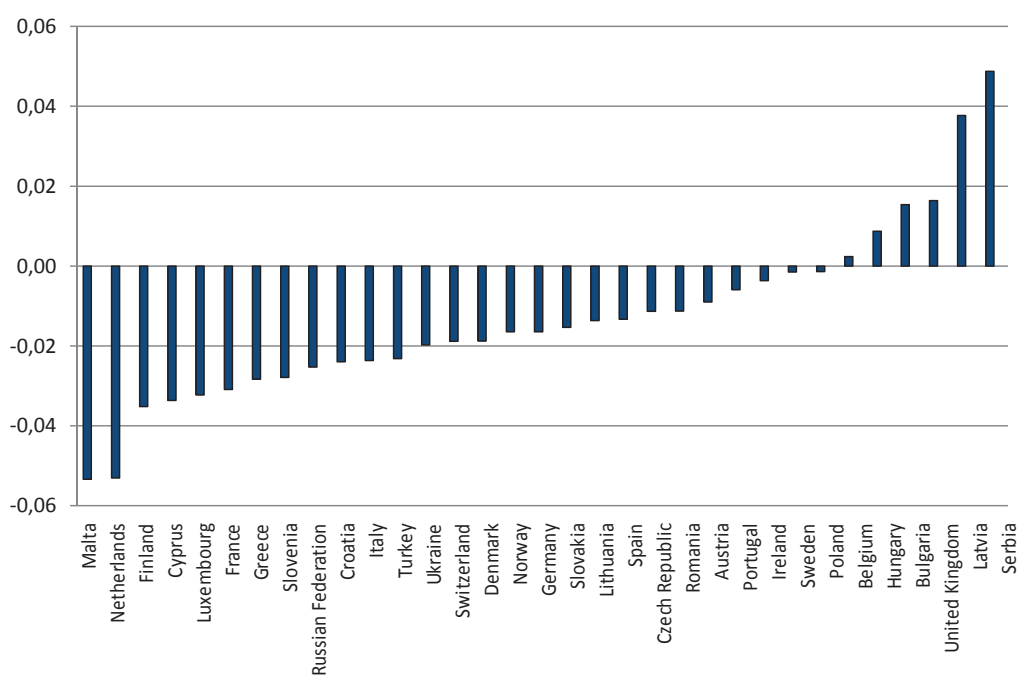

Panel B: SRISK

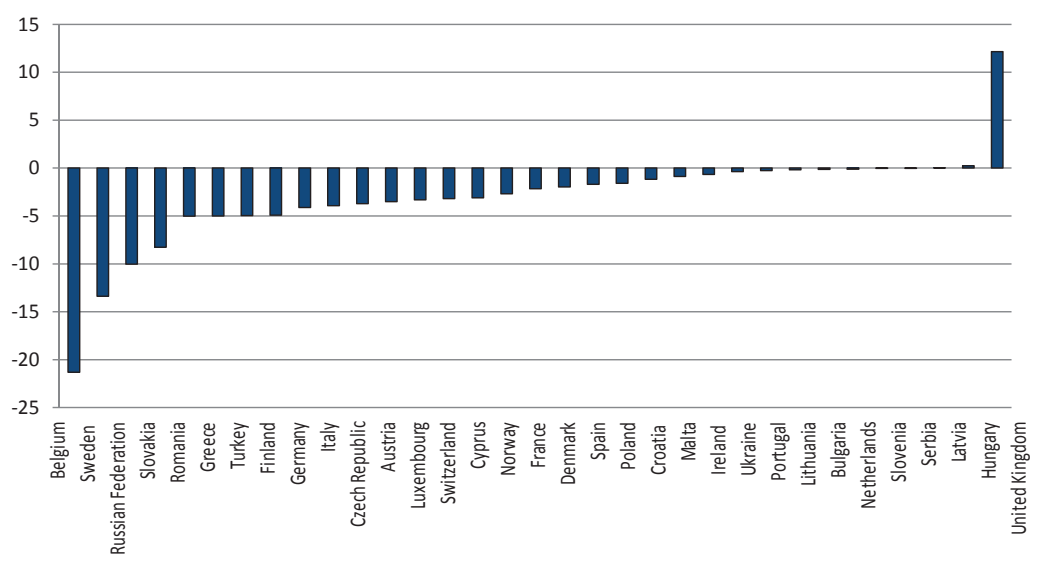

Panel C: Delta CoVaR

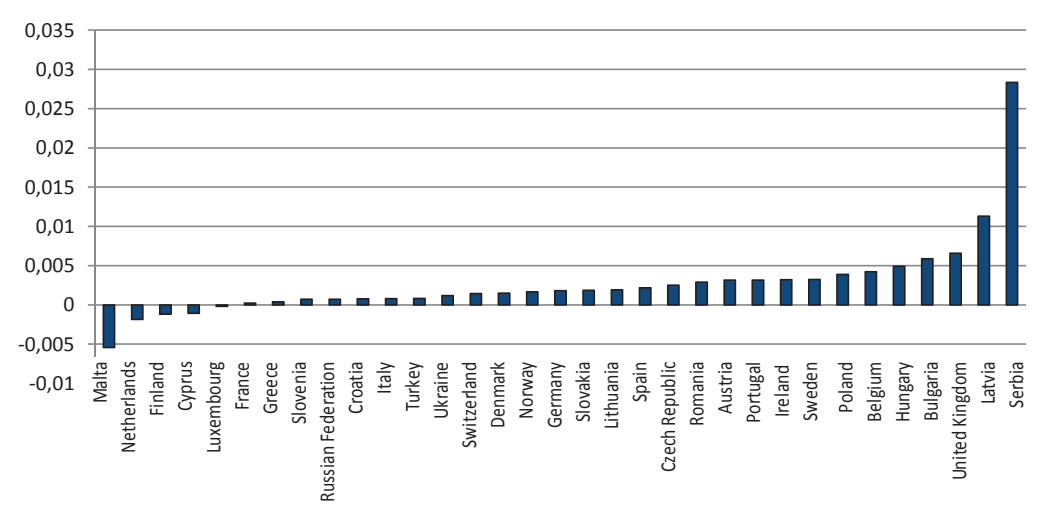


Figure 5: Comparison of the systemic risk exposure and contribution of European and U.S. banks, 1991-2011

The figures plot the average dynamic Marginal Expected Shortfall (MES), SRISK and $\Delta$ CoVaR estimates of U.S. banks against corresponding estimates of matching European banks between 1991 and 2011. The MES estimates are averaged annually from daily MES estimates computed by the use of the dynamic model proposed by Brownlees and Engle (2012). The SRISK estimates are computed using the methodology laid out by Brownlees and Engle (2012) and Acharya et al. (2012) while the (conditional) $\triangle \mathrm{CoVaR}$ estimates are computed as described in Appendix $\mathrm{A}$.

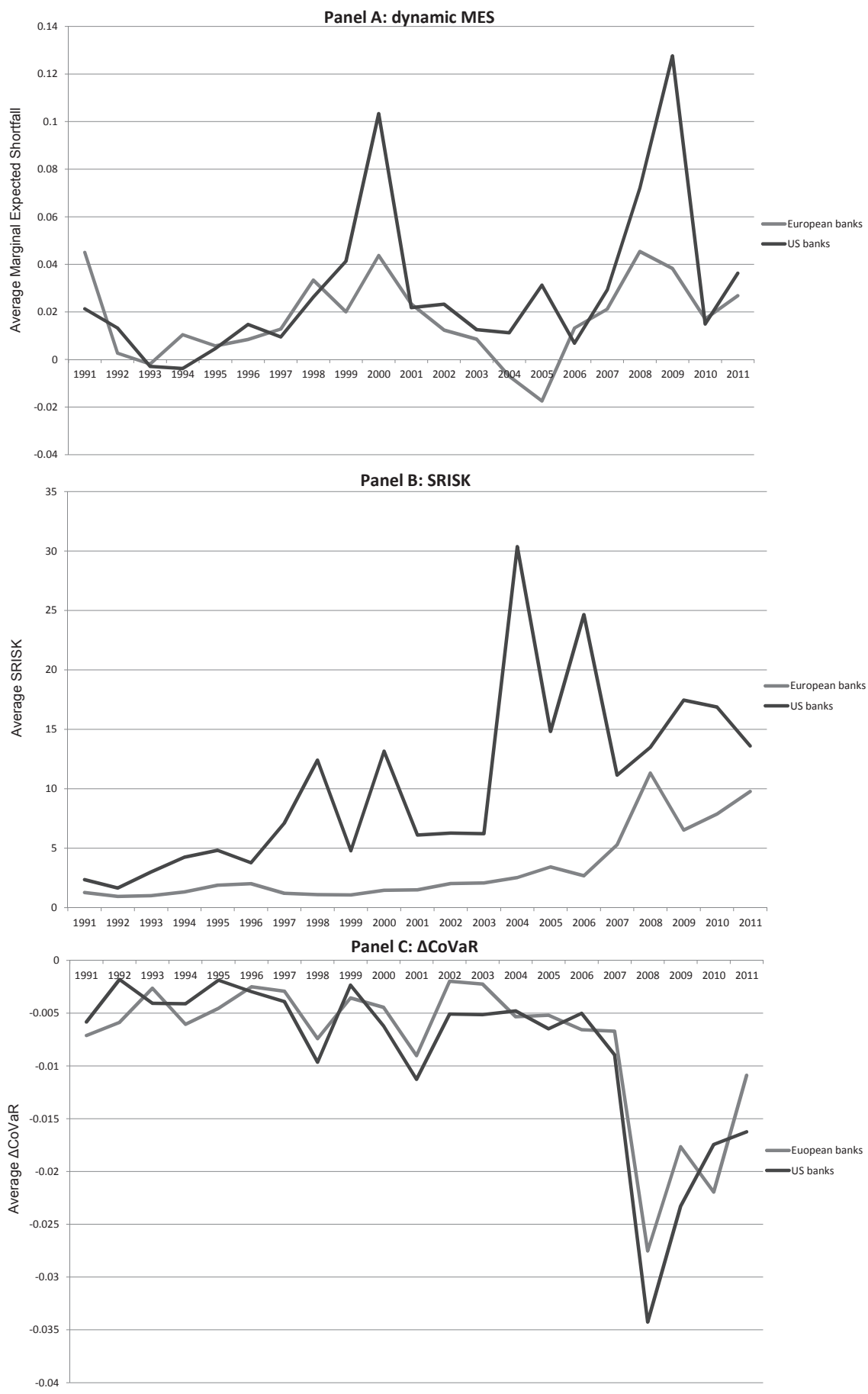




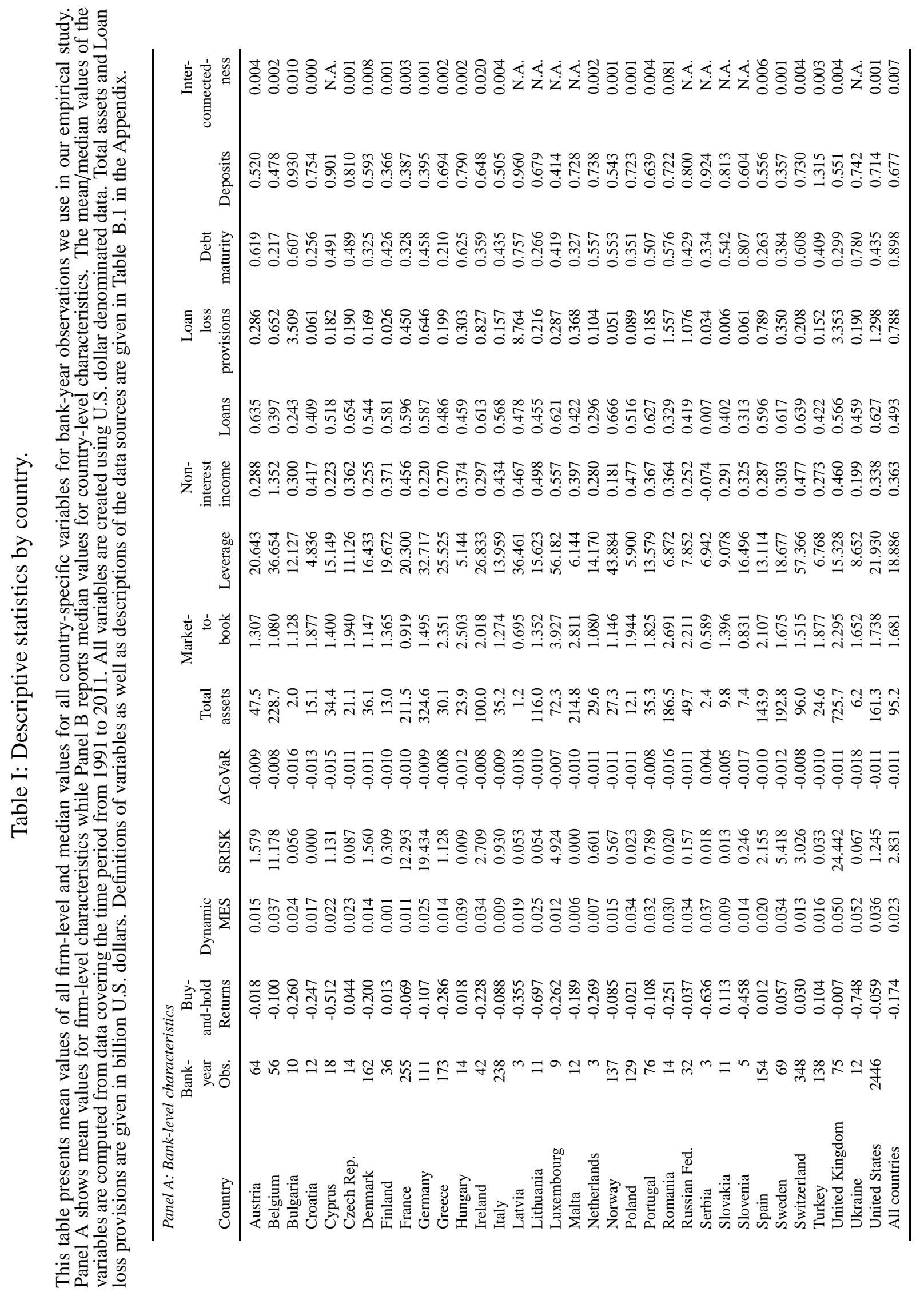




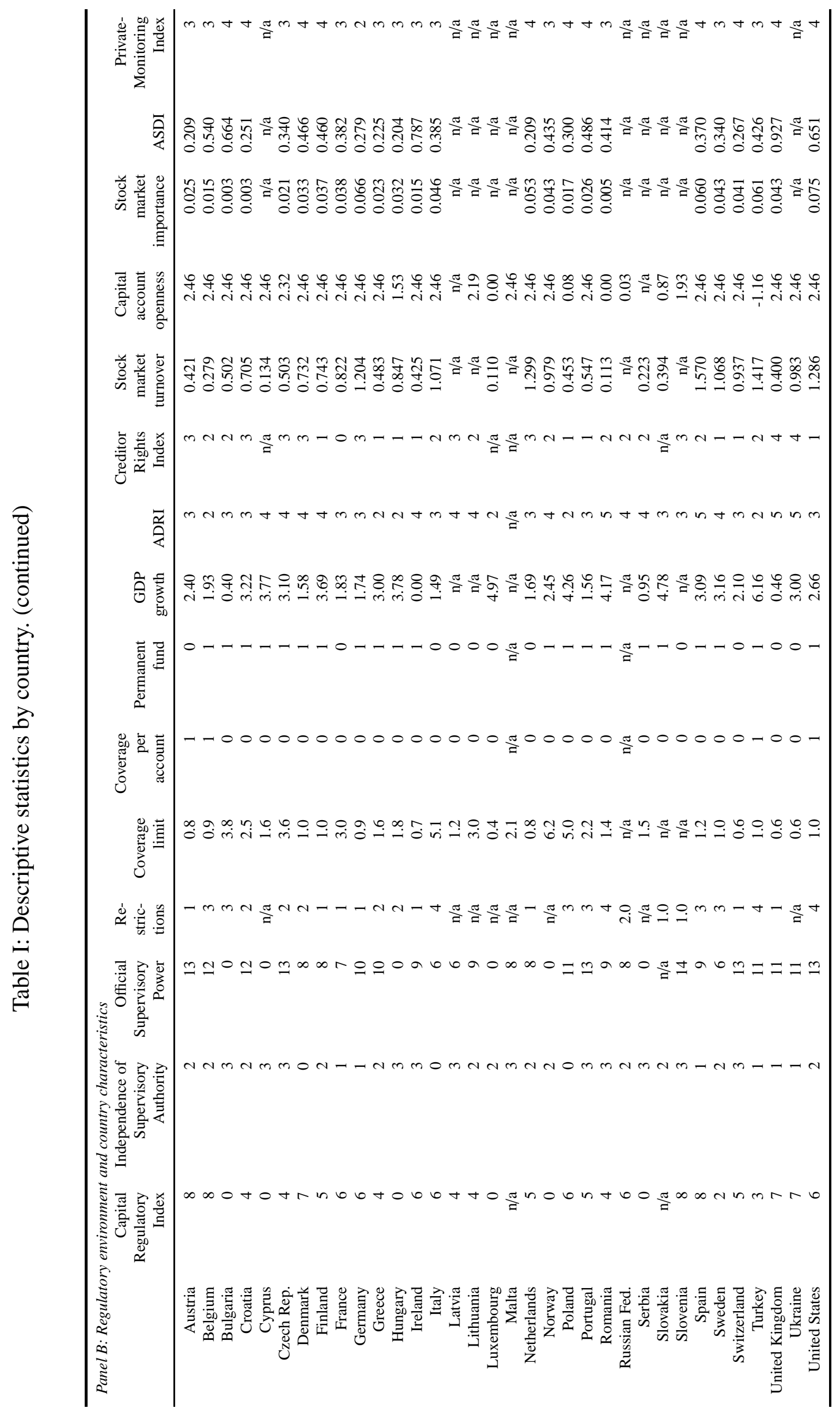




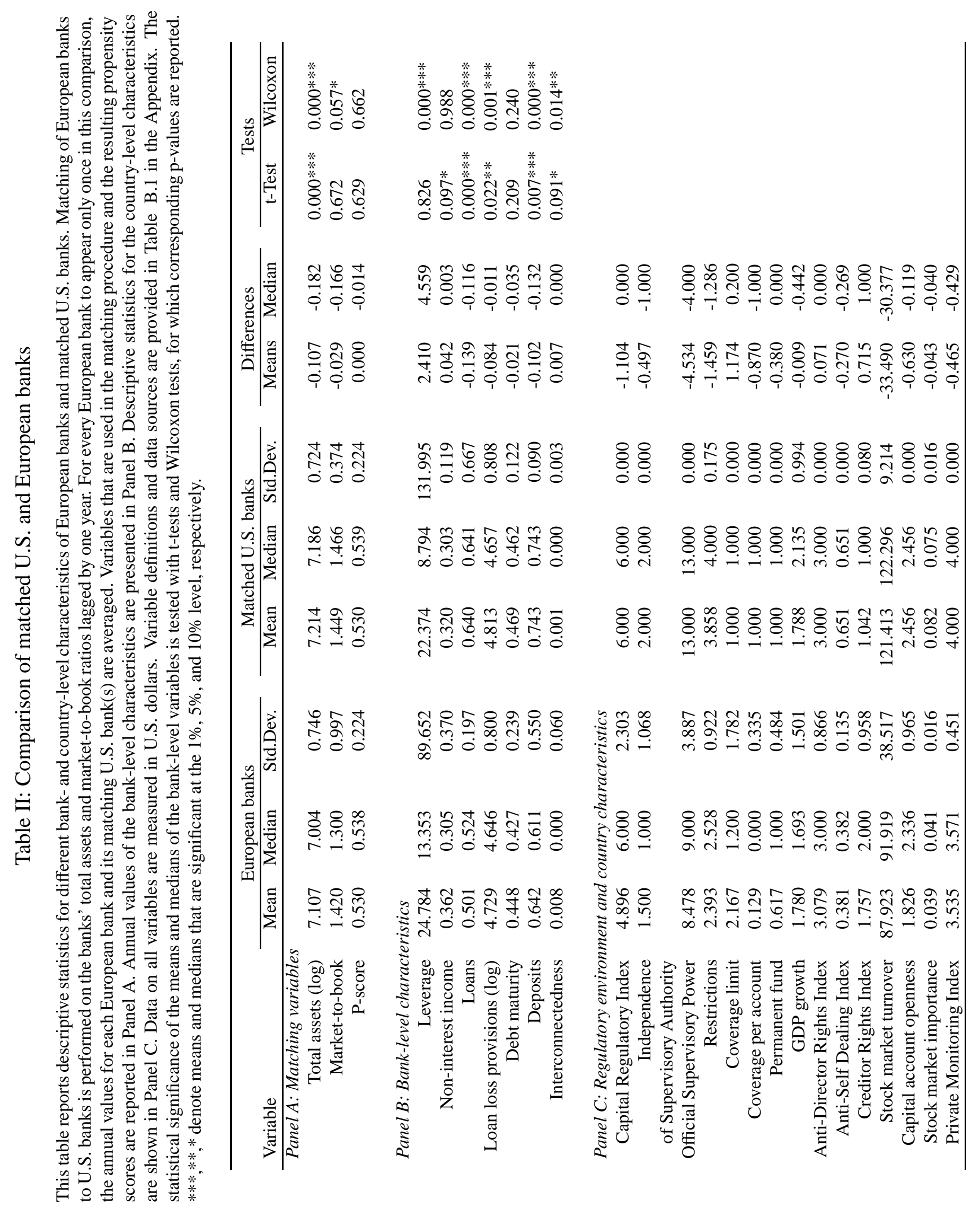




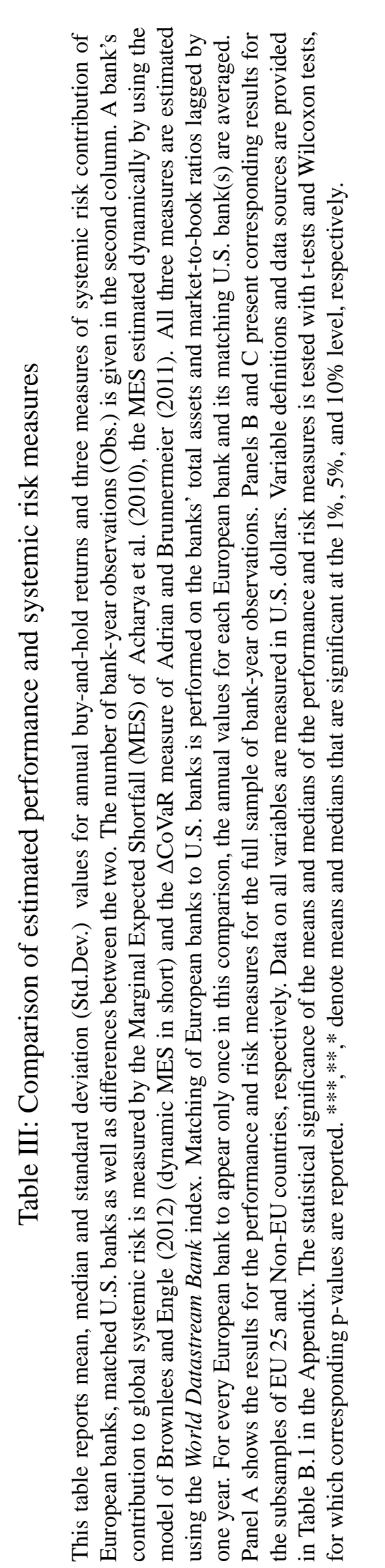

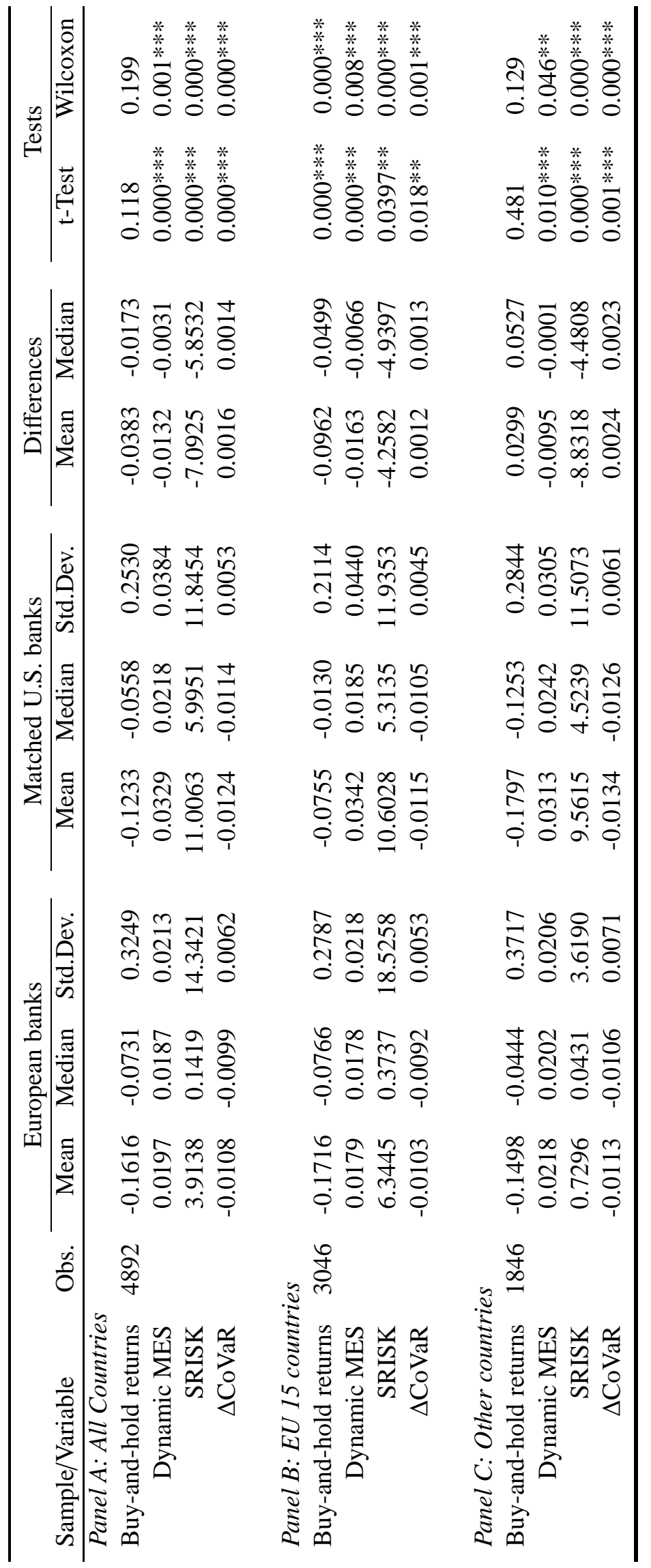


Table IV: Comparison of performance and systemic risk measures over time

This table reports mean differences in annual buy-and-hold returns and three measures of systemic risk contribution of European banks and matched U.S. banks by year. A bank's contribution to global systemic risk is measured by the Marginal Expected Shortfall (MES) of Acharya et al. (2010), the MES estimated dynamically by using the model of Brownlees and Engle (2012) (dynamic MES in short) and the $\triangle \mathrm{CoVaR}$ measure of Adrian and Brunnermeier (2011). All three measures are estimated using the World Datastream Bank index. Matching of U.S. banks (with replacement) to European banks is performed on the banks' total assets and market-to-book ratios lagged by one year. For every European bank to appear only once in this comparison, the annual values for each European bank and its matching U.S. bank(s) are averaged. Data on all variables are measured in U.S. dollars. Variable definitions and data sources are provided in Table B.1 in the Appendix. The statistical significance of the means of the performance and risk measures is tested with t-tests, for which corresponding $\mathrm{p}$-values are reported. $* * *, * * *$ denote means that are significant at the $1 \%, 5 \%$, and $10 \%$ level, respectively.

\begin{tabular}{|c|c|c|c|c|c|c|c|c|}
\hline & \multirow{2}{*}{\multicolumn{2}{|c|}{ Buy-and-Hold Returns }} & \multicolumn{2}{|l|}{ Dynamic MES } & \multicolumn{2}{|l|}{ SRISK } & \multicolumn{2}{|l|}{$\Delta \mathrm{CoVaR}$} \\
\hline & & & Mean Difference & & Mean Difference & & Mean Difference & \\
\hline \multirow[t]{2}{*}{1991} & -0.453 & **** & 0.024 & *** & -1.044 & *** & -0.001 & \\
\hline & $(0.000)$ & & $(0.033)$ & & $(0.042)$ & & $(0.242)$ & \\
\hline \multirow[t]{2}{*}{1992} & -0.353 & $* * *$ & 0.011 & * & -0.702 & $*$ & -0.004 & $* * *$ \\
\hline & $(0.000)$ & & $(0.059)$ & & $(0.083)$ & & $(0.001)$ & \\
\hline \multirow[t]{2}{*}{1993} & 0.337 & $* * *$ & 0.001 & & -1.983 & $* * *$ & 0.001 & $* * *$ \\
\hline & $(0.000)$ & & $(0.541)$ & & $(0.000)$ & & $(0.005)$ & \\
\hline \multirow[t]{2}{*}{1994} & -0.058 & * & -0.016 & $* * *$ & -2.995 & $* * *$ & -0.002 & * \\
\hline & $(0.061)$ & & $(0.005)$ & & $(0.000)$ & & $(0.047)$ & \\
\hline \multirow[t]{2}{*}{1995} & -0.441 & $* * *$ & -0.002 & & -2.936 & $* * *$ & -0.003 & *** \\
\hline & $(0.000)$ & & $(0.450)$ & & $(0.000)$ & & $(0.000)$ & \\
\hline \multirow[t]{2}{*}{1996} & -0.137 & $* * *$ & 0.008 & $* * *$ & -2.080 & $* * *$ & 0.000 & \\
\hline & $(0.000)$ & & $(0.005)$ & & $(0.000)$ & & $(0.345)$ & \\
\hline \multirow[t]{2}{*}{1997} & -0.008 & & -0.004 & $*$ & -5.894 & $* * *$ & 0.001 & \\
\hline & $(0.842)$ & & $(0.098)$ & & $(0.000)$ & & $(0.141)$ & \\
\hline \multirow[t]{2}{*}{1998} & 0.167 & $* * *$ & -0.007 & * & -11.315 & $* * *$ & 0.002 & $* *$ \\
\hline & $(0.001)$ & & $(0.094)$ & & $(0.000)$ & & $(0.013)$ & \\
\hline \multirow[t]{2}{*}{1999} & 0.435 & $* * *$ & -0.004 & & -3.716 & $* * *$ & -0.001 & $* * *$ \\
\hline & $(0.000)$ & & $(0.288)$ & & $(0.000)$ & & $(0.000)$ & \\
\hline \multirow[t]{2}{*}{2000} & -0.140 & $* * *$ & -0.072 & ** & -11.705 & $* * *$ & 0.002 & $* * *$ \\
\hline & $(0.000)$ & & $(0.019)$ & & $(0.000)$ & & $(0.001)$ & \\
\hline \multirow[t]{2}{*}{2001} & -0.141 & $* * *$ & 0.001 & & -4.610 & $* * *$ & 0.002 & $* *$ \\
\hline & $(0.000)$ & & $(0.610)$ & & $(0.000)$ & & $(0.011)$ & \\
\hline \multirow[t]{2}{*}{2002} & -0.225 & $* * *$ & -0.010 & $* * *$ & -4.220 & $* * *$ & 0.003 & $* * *$ \\
\hline & $(0.000)$ & & $(0.000)$ & & $(0.000)$ & & $(0.000)$ & \\
\hline \multirow[t]{2}{*}{2003} & -0.076 & $* *$ & -0.006 & $* * *$ & -4.144 & $* * *$ & 0.003 & $* * *$ \\
\hline & $(0.012)$ & & $(0.004)$ & & $(0.000)$ & & $(0.000)$ & \\
\hline \multirow{2}{*}{2004} & 0.074 & $* * *$ & -0.004 & $* * *$ & -27.844 & $* * *$ & -0.001 & \\
\hline & $(0.000)$ & & $(0.002)$ & & $(0.000)$ & & $(0.227)$ & \\
\hline \multirow[t]{2}{*}{2005} & 0.276 & $* * *$ & -0.064 & $* * *$ & -11.404 & $* * *$ & 0.001 & $* * *$ \\
\hline & $(0.000)$ & & $(0.000)$ & & $(0.000)$ & & $(0.002)$ & \\
\hline \multirow[t]{2}{*}{2006} & 0.101 & $* * *$ & 0.008 & $* * *$ & -21.885 & $* * *$ & -0.002 & $* * *$ \\
\hline & $(0.000)$ & & $(0.000)$ & & $(0.000)$ & & $(0.000)$ & \\
\hline \multirow[t]{2}{*}{2007} & -0.145 & * & -0.007 & $* *$ & -5.975 & $* * *$ & 0.002 & $* * *$ \\
\hline & $(0.069)$ & & $(0.015)$ & & $(0.000)$ & & $(0.000)$ & \\
\hline \multirow[t]{2}{*}{2008} & -0.297 & $* * *$ & -0.017 & $* * *$ & -2.113 & & 0.007 & $* * *$ \\
\hline & $(0.001)$ & & $(0.002)$ & & $(0.000)$ & & $(0.000)$ & \\
\hline \multirow[t]{2}{*}{2009} & 0.615 & $* * *$ & -0.104 & $* * *$ & -10.975 & $* * *$ & 0.006 & $* * *$ \\
\hline & $(0.000)$ & & $(0.000)$ & & $(0.000)$ & & $(0.000)$ & \\
\hline 2010 & -0.145 & $* * *$ & 0.005 & & -8.941 & $* * *$ & -0.005 & $* * *$ \\
\hline & $(0.001)$ & & $(0.161)$ & & $(0.000)$ & & $(0.000)$ & \\
\hline 2011 & -0.267 & $* * *$ & -0.009 & $* * *$ & -3.429 & $* * *$ & 0.005 & $* * *$ \\
\hline & $(0.000)$ & & $(0.001)$ & & $(0.000)$ & & $(0.000)$ & \\
\hline
\end{tabular}




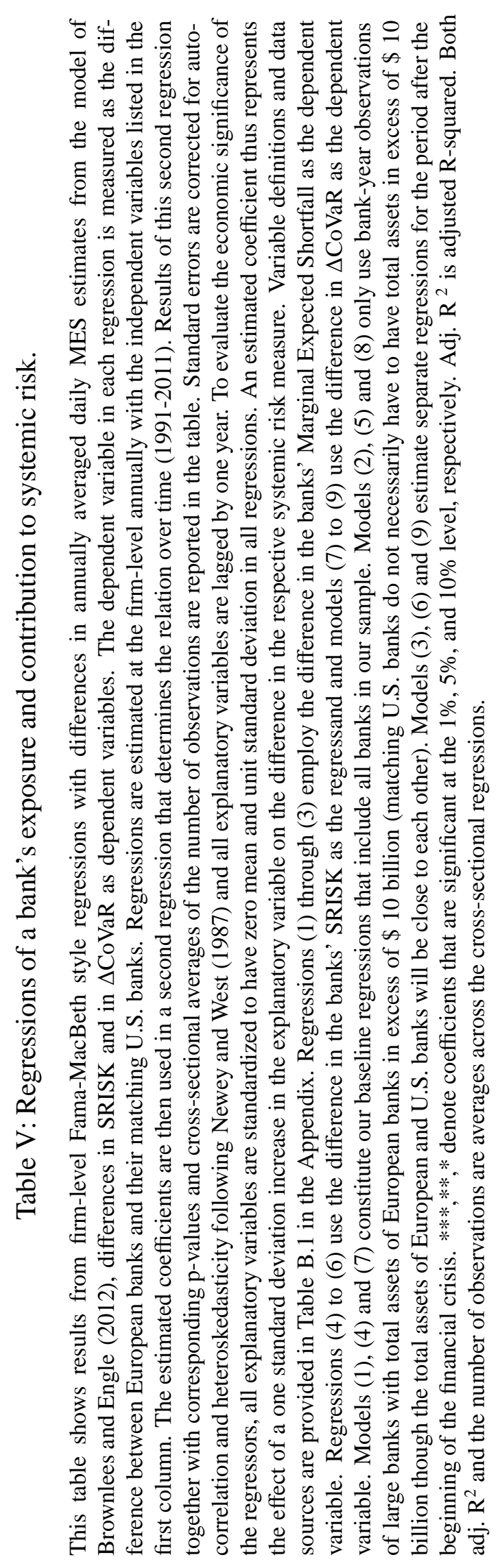




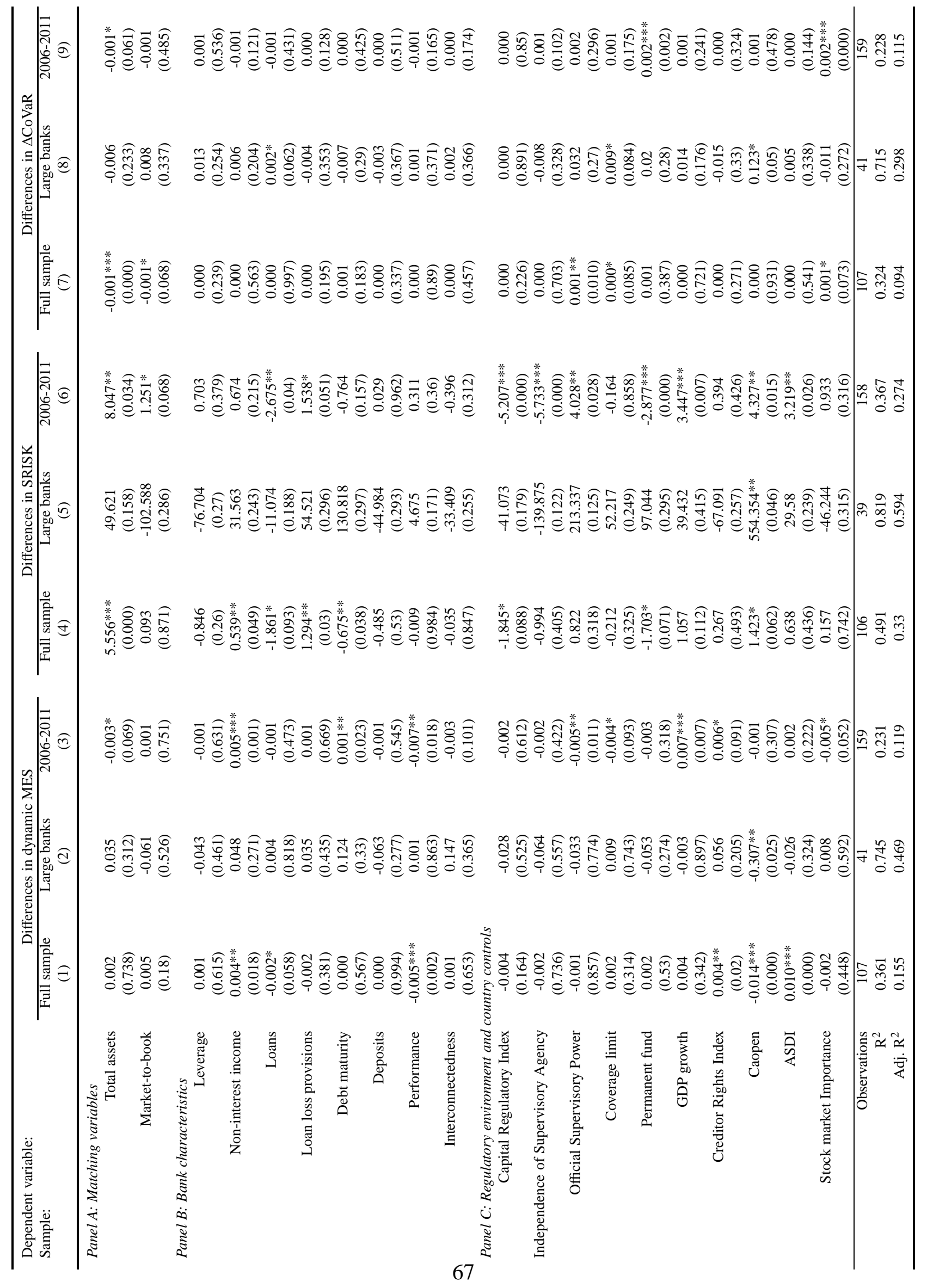




